\title{
Evolution of the hectocotylus in Sepiolinae (Cephalopoda: Sepiolidae) and description of four new genera
}

\author{
Giambattista BELLO \\ Arion, Via Colombo 34, 70042 Mola di Bari, Italy. \\ giamb.bello@gmail.com \\ urn:1sid:zoobank.org:author:31A50D6F-5126-48D1-B630-FBEDA63944D9 \\ ....it is impossible to doubt that the [hectocotylized] arm \\ is thereby adapted to some particular purpose, \\ $[\ldots]$ because its transformation occurs \\ in so great a number of species of the class, \\ and bears its peculiar characters in each natural genus.
}

Japetus Steenstrup (1857)

\begin{abstract}
The subfamily Sepiolinae (Mollusca: Cephalopoda: Sepiolidae), currently containing the genera Sepiola Leach, 1817, Euprymna Steenstrup, 1887, Inioteuthis Verrill, 1881, Rondeletiola Naef, 1921 and Sepietta Naef, 1912, is characterized by the hectocotylization of the left dorsal arm, i.e., its transformation into a copulatory organ thanks to modifications of sucker/pedicel elements. The hectocotylus morphology varies to a great extent across genera and species. In particular, one to several pedicels in its proximal third lose their sucker and become highly and diversely modified in shape to constitute a copulatory apparatus. An evolutionary gradient was observed in the copulatory apparatus morphology, from the simple modification into a papilla of just one pedicel from the third element of the ventral sucker row (some nominal species of Euprymna) to a quite complex structure involving several variously modified pedicels from both the ventral and dorsal sucker rows (Inioteuthis). In some species, elements in the distal portion of the hectocotylus may also be highly modified, such as the columnar suckers in Euprymna. The hectocotylian diversity allows to distinguish nine groups of species that do not match the current generic subdivision of Sepiolinae. Additional morphological characters (number of sucker rows on arms, female bursa copulatrix, occurrence and shape of visceral light organs, etc.) corroborate the subdivision of Sepiolinae into nine subtaxa, i.e., genera. Accordingly, a cladogram is drawn to describe the possible phylogenetic relationships among the nine clades. To comply with these results, all current genera are redefined and four new genera are described, namely Adinaefiola gen. nov., Boletzkyola gen. nov., Eumandya gen. nov. and Lusepiola gen. nov.
\end{abstract}

Keywords. Mollusca, copulatory organs, systematics, phylogeny, key to genera.

Bello G. 2020. Evolution of the hectocotylus in Sepiolinae (Cephalopoda: Sepiolidae) and description of four new genera. European Journal of Taxonomy 655: 1-53. https://doi.org/10.5852/ejt.2020.655 


\section{Introduction}

The subfamily Sepiolinae Leach, 1817 is one of three subtaxa into which the family Sepiolidae Leach, 1817 (Cephalopoda: Sepiolida) is currently subdivided; the other two are Heteroteuthinae Appellöf, 1898 and Rossiinae Appellöf, 1898 (Reid \& Jereb 2005). However, the discovery of new genera has revealed problems with the present taxonomic organization at the subfamilial level (Lu \& BoucherRodoni 2006; Young et al. 2006). In addition, the results of genetic studies have indicated that the monophyly of Heteroteuthinae is questionable (Lindgren et al. 2012; Allcock et al. 2014). Contrary to this, Sepiolinae is generally deemed a homogeneous, i.e., monophyletic, taxon. This is because of some features shared by all its member genera, including the unique bursa copulatrix in females (a structure beside the gonoduct opening into which males deposit spermatophores) and similarities in the gross morphology of the matching hectocotylus (left dorsal arm modified for copulation) in males. Other characters (although not unique to Sepiolinae) include: the dorsal mantle fused with head in the nuchal region; the interbrachial web present only between arms I-III, and weakly developed; the tentacular club expanded with a keel along its full length; and the gladius weakly developed or completely reduced (Naef 1923). The monophyly of Sepiolinae has also been corroborated by genetic analyses (Nishiguchi et al. 2004; Lindgren et al. 2012; Allcock et al. 2014).

Five genera are currently recognized in Sepiolinae: Euprymna Steenstrup, 1887, Inioteuthis Verrill, 1881, Rondeletiola Naef, 1921, Sepietta Naef, 1912 and Sepiola Leach, 1817 (Reid \& Jereb 2005). The overall number of species reported in MolluscaBase (2018a, 2018b, 2018c, 2018d, 2018e) is 36 , but a few are possibly invalid (see below). The diagnostic characters used to separate genera and species in this subfamily include the presence and shape of the mantle cavity light organs, the number of longitudinal sucker rows on the arms and tentacle clubs, the pattern of enlarged suckers on the arms, the morphology of the male hectocotylus and the shape of the female bursa copulatrix. Their geographical distribution, as revised by Reid \& Jereb (2005), indicates some disjunction among the nominal genera, with Euprymna and Inioteuthis occurring in the Indo-Pacific region, Rondeletiola and Sepietta inhabiting the eastern Atlantic Ocean and the Mediterranean Sea, whereas Sepiola is found in both the east Atlantic-Mediterranean region and the Indo-Pacific. No sepioline species occurs along either coast of North and South America.

The monophyly of the genus Sepiola was questioned by Bello (2005) due to morphological differences in the hectocotylus between the group of northeast Atlantic-Mediterranean species known at that time, namely affinis Naef, 1912, atlantica d'Orbigny, 1842, aurantiaca Jatta, 1896, intermedia Naef, 1912, ligulata Naef, 1912, robusta Naef, 1912, rondeletii Leach, 1817 and steenstrupiana Levy, 1912, and the group of Indo-Pacific species, namely birostrata Sasaki, 1918, trirostrata Voss, 1962 and parva Sasaki, 1914 (the latter currently in Euprymna; Sanchez et al. 2019). The former group appeared to share more affinities with the genera Rondeletiola and Sepietta than with the latter group. Consequently, the same paper advocated the placement of the Atlantic-Mediterranean and the Indo-Pacific groups of species of Sepiola into two separate genera (Bello 2005). Accordingly, a need to create a new genus, to accommodate the latter group of species, was assumed. This finding was also supported by genetic analyses in Nishiguchi et al. (2004), which showed that the Indo-Pacific Sepiola birostrata is more closely related to Euprymna than to its Atlantic-Mediterranean congeneric species. Later on, Lindgren et al. (2012) and Sanchez et al. (2019) corroborated that result. Moreover, Lindgren et al. (2012) also found that Sepiola ligulata does not cluster closely with other Atlantic-Mediterranean species of Sepiola. A similar situation had also been pointed out by Groenenberg et al. (2009). In summary, and despite numerous misidentifications of specimens used in genetic research as emphasized by several authors (e.g., Groenenberg et al. 2009; Lindgren et al. 2012; Allcock et al. 2014; Sanchez et al. 2019), all the above reported molecular studies lead to the same conclusion: the generic level systematics of Sepiolinae needs a thorough review. 
The above-cited preliminary study by Bello (2005) encouraged further examination of hectocotyli, as well as of other characters, in several more species from all sepioline genera. The reason for electing the male copulatory arm as the main organ to understand Sepiolinae phylogeny was based on the repeated substantiation by Adolf Naef of the paramount role of the hectocotylus in discriminating all the northeastern Atlantic-Mediterranean sepioline species available to him. Thanks to his work on hectocotyli, he succeeded in describing two new genera and seven new species of Sepiolinae (Naef 1912a, 1912b, 1912c, 1916, 1921, 1923). In recent times, new species of Sepiola from the same geographical region have been discovered during routine examinations of hectocotyli (Bello 2013; Bello \& Salman 2015) or confirmed to be new by hectocotylian distinctiveness following molecular indications (de Heij \& Goud 2010). Indeed, the hectocotylus appears to play a role in speciation within Sepiolinae, since it is one of the two elements in the genus- and species-specific lock-and-key copulatory mechanism that limits extra-specific fertilization (Bello 2019a). Incidentally, the high specific variability of male copulatory organs is a feature widely distributed among disparate taxa (e.g., Simmons 2014; Azevedo et al. 2018).

To the best of my knowledge, the first representation of a sepioline hectocotylus (though not accounted for) can be found in Rondelet's Libri de Piscibus Marinis (Rondeletius 1554: 519) (Fig. 1). However, Japetus Steenstrup was the first scientist to recognize the systematic relevance of the hectocotylus that "bears its peculiar characters in each natural genus" (Steenstrup 1857: 82). In that paper, Steenstrup displayed the first drawing of a correctly interpreted Sepiola hectocotylus (Fig. 2) and even went ahead by explaining the function of the "remarkable dilatation of the skin developed at the base of the inner surface of the arm [i.e., the copulatory apparatus, see below], strongly provided with muscles, and thus rendered capable of dilating itself towards the sides and folding itself together, so that it appears able to act as a prehensile apparatus or forceps" (Steenstrup 1857: 92). Thirty years later, Steenstrup (1887b) revisited the significance of hectocotylization. He sternly put forth the motivation of his paper by means of the following epigraph in Latin, "Hectocotylatio ab iniquitatibus J. Brockii, A. E. Verrilli, A. Appellöf aliorumque vindicata. Hectocotylatio bene observata et rite considerata divisionibus naturce semper congruit, incongrua divisionibus, eas arbitrarias et factitias esse indicat" (Steenstrup 1887b). (Translation: Hectocotylization avenged from the crimes by J. Brock, A. E. Verrill, A. Appellöf and others. The well-observed and duly-pondered hectocotylization is always congruent with the classification of nature, when incongruent with a classification it indicates that the latter is arbitrary and fictitious.)

In a sense, Steenstrup passed the baton, so to speak, to Adolf Naef. The latter was the first author to describe and figure the diversity of the hectocotylized arm in several sepioline species (Naef 1912b) (Fig. 3). In that work, he assigned a particular diagnostic value to the hectocotylus Basalapparat (basal apparatus), a group of highly modified sucker pedicels in the proximal third of the arm; the Basalapparat was afterwards renamed apparatus copulator (copulatory apparatus) by Naef (1916) himself. Later, Naef (1923) explicitly stated that this formation has "a special function during copulation when the arm is introduced into the mantle cavity of the female for the transfer of the spermatophores." At this time, he

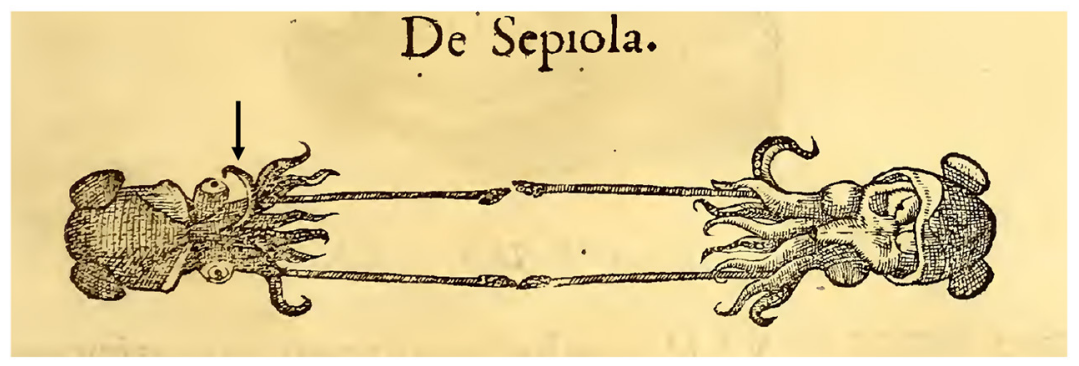

Fig. 1. Sepiola depiction in Libri de Piscibus Marinis (Rondeletius 1554: 519), modified. The arrow points to the hectocotylized arm (left arm I). 


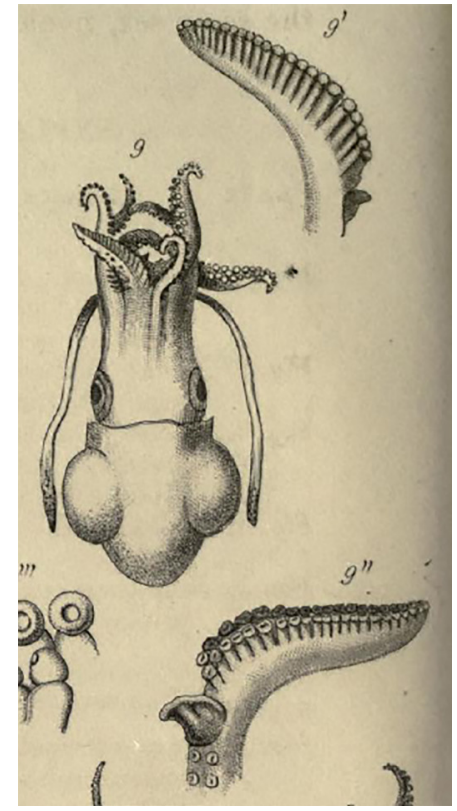

Fig. 2. "Sepiola Rondeletii" (fig. 9) and its hectocotylus (figs 9' and 9") figured by Steenstrup (1857: plate II). Despite some inaccuracies (fig. 9: the mantle border is not fused with the head; fig. 9': no sucker is enlarged in the dorsal row of the distal part; fig. 9": four suckers are depicted in the hectocotylus basal part instead of three), the copulatory apparatus of the hectocotylus - "remarkable dilatation of the skin" according to Steenstrup - (fig. 9") clearly pertains to a species of the Sepiola atlantica-group.

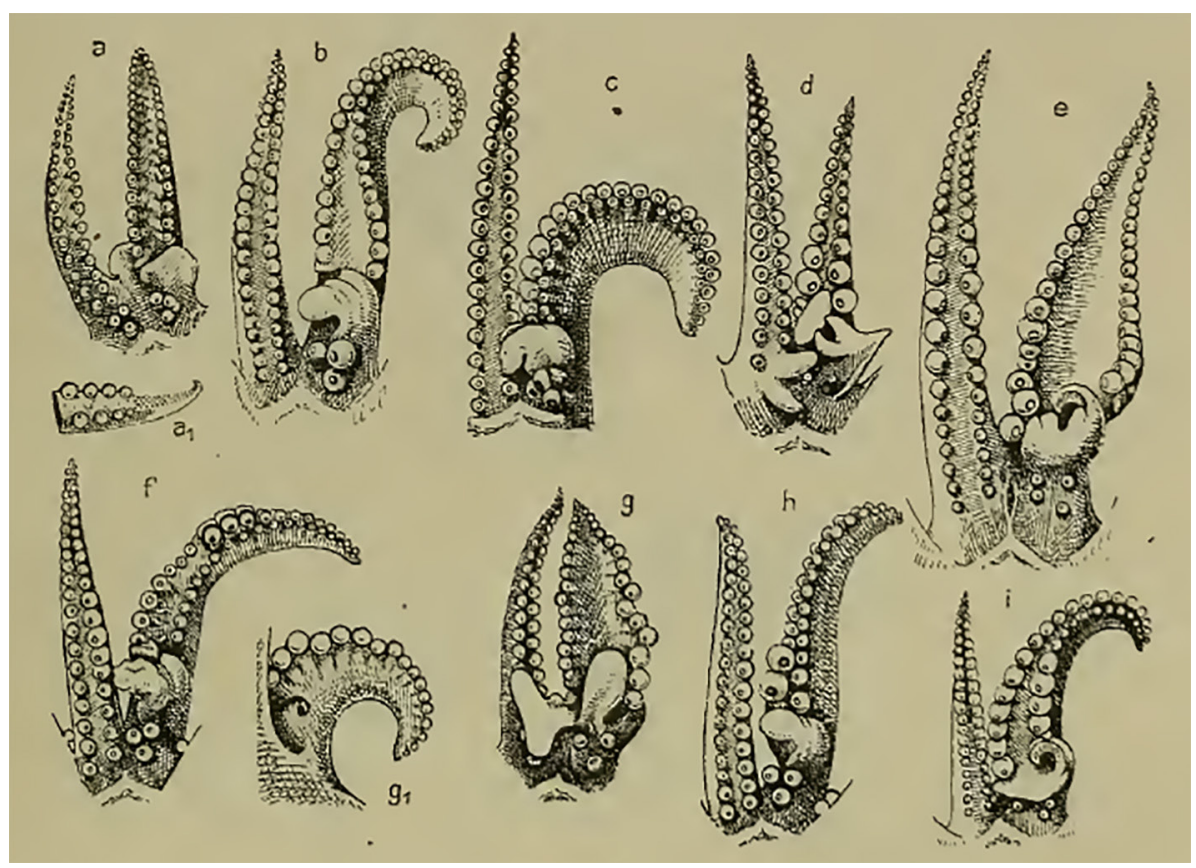

Fig. 3. The sepioline hectocotylus diversity displayed by Naef (1912b: fig. 1). The drawings, left to right starting from upper row, show the pair of dorsal arms (the hectocotylus is that on the right side) of Sepiola steenstrupiana Levy, 1912, Sepiola robusta Naef, 1912, Sepiola rondeletii Leach, 1817, Sepiola aurantiaca Jatta, 1896, Sepietta oweniana (d'Orbigny, 1841), Sepiola atlantica d'Orbigny, 1842, Sepiola ligulata Naef, 1912, Sepiola intermedia Naef, 1912 and Rondeletiola minor (Naef, 1912). 
also showed the correspondence between the specific form of the hectocotylus and the bursa copulatrix (copulatory pouch) in different species, which is to be understood with reference to copulation. Naef (1923: 563) described the typical hectocotylus of the 'Sepiola-like Eusepiolinae' (that is the genera Sepiola, Inioteuthis, Rondeletiola and Sepietta) as follows: "Left dorsal arm of male markedly modified, with 1-4 regular suckers at the base, followed by a 'copulatory apparatus' of modified stalks of suckers and with a zone of more or less regular suckers in the distal part." Incidentally, the formally defined taxon Eusepiolinae Naef, 1923, nested in Sepiolinae (hence at the tribe rank), contained Euprymna in addition to the above Sepiola-like genera (Naef 1923). The name Eusepiolinae was apparently used only by Naef (1923). As for the ontogeny of the hectocotylus, the examination of maturing males clearly shows that the pedicels involved in the copulatory apparatus formation lose their suckers and progressively undergo the modifications (lengthening, curving and so on) specific to each species; these modifications appear to be homochronous to the development of the internal genital organs (author's pers. obs.).

With regard to the bursa copulatrix, Steenstrup (1900) was, once again, the first author to explicitly depict it and explain its function, despite the fact that in his figures 11 and 13 of the posthumous plate he wrongly identified the species depicted (his purported "Sepiola Rondeletii" is not readily ascribable to any species of Sepiola, whereas "Sepiola Petersii" probably corresponds to Sepietta oweniana; cf. Bello 2011) (Fig. 4).

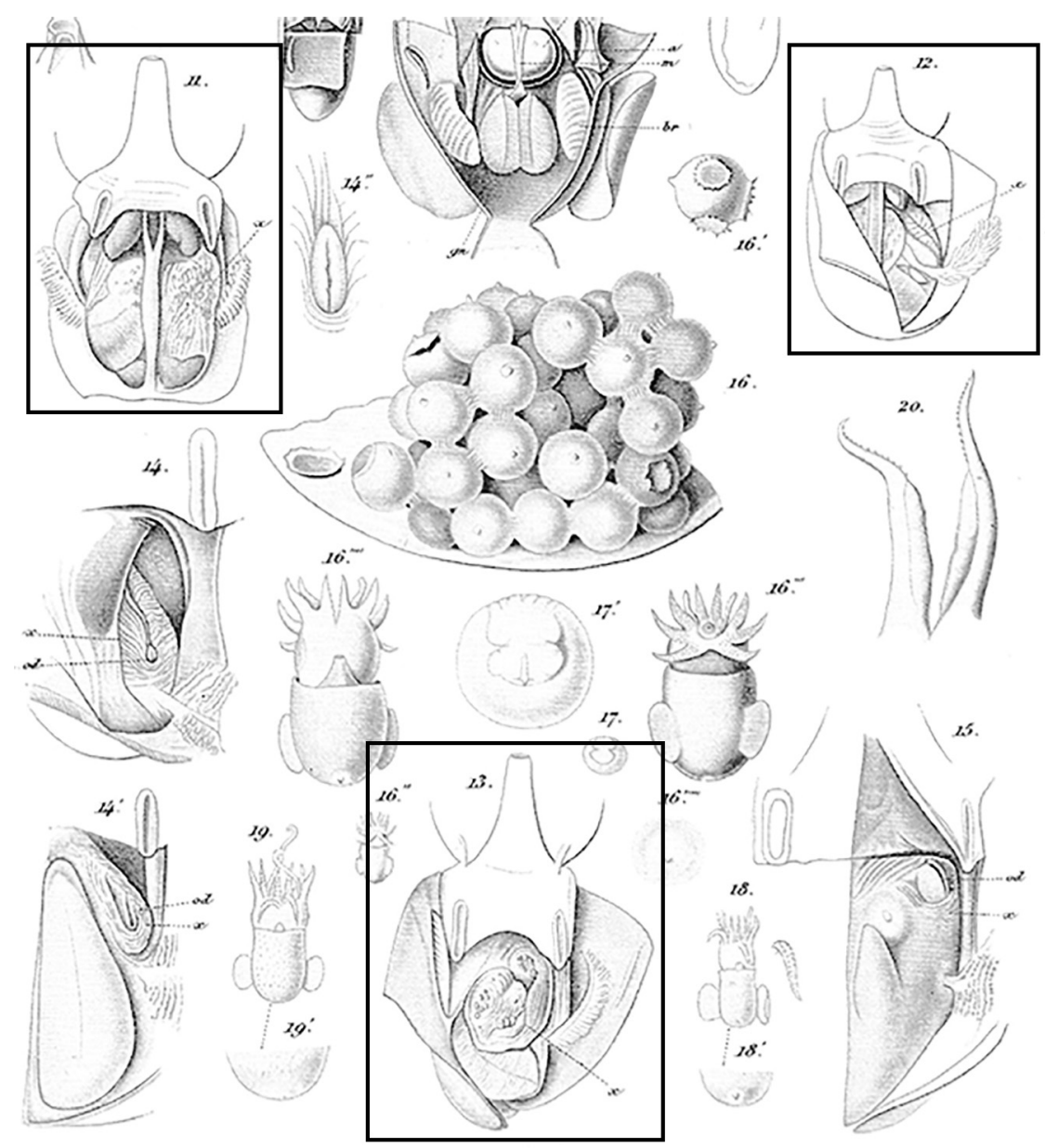

Fig. 4. Sepioline bursae copulatrices (x) depicted by Steenstrup (1900) (highlighted by rectangular frames). The species reported are "Sepiola Rondeletii" (fig. 11), Sepiola sp. (fig. 12) and "Sepiola Petersii" (fig. 13). 
Naef (1923) was also the first teuthologist to define a 'genealogical tree' of Sepiolidae. In it, he situated Euprymna in a basal position with respect to Sepiola, Inioteuthis, Rondeletiola and Sepietta; the latter two genera were placed on the terminal forked branch stemming from Sepiola (Fig. 5). In recent times, a somewhat similar cladogram was drawn after a cladistic analysis of some anatomical characters (Bello 1998) (that analysis did not include Inioteuthis). Also according to Nishiguchi et al. (2004) and Young (2007), Euprymna holds a basal position as opposed to all other genera.

A few phylogenetic molecular-based trees have been produced by several authors (e.g., Nishiguchi et al. 2004; Groenenberg et al. 2009; Lindgren et al. 2012; Allcock et al. 2014; Sanchez et al. 2019), but none of them includes all the sub-clades of Sepiolinae (for instance, Inioteuthis is lacking from all of them), which, in addition to drawbacks caused by misidentifications (see above), has not allowed the overall resolution of the sepioline tree. Moreover, Sepiolinae molecular phylogenetic studies have not been paralleled by morphology-based works, apart from descriptions of a few new species (see below).

As a consequence of the above described situation, a thorough review of hectocotyli diversity in Sepiolinae is warranted in order (i) to examine the likely evolutionary trends in hectocotylus morphology in this subfamily and (ii) to revise the systematics of this subfamily based on the structure of the hectocotylus as well as on additional morphological traits.

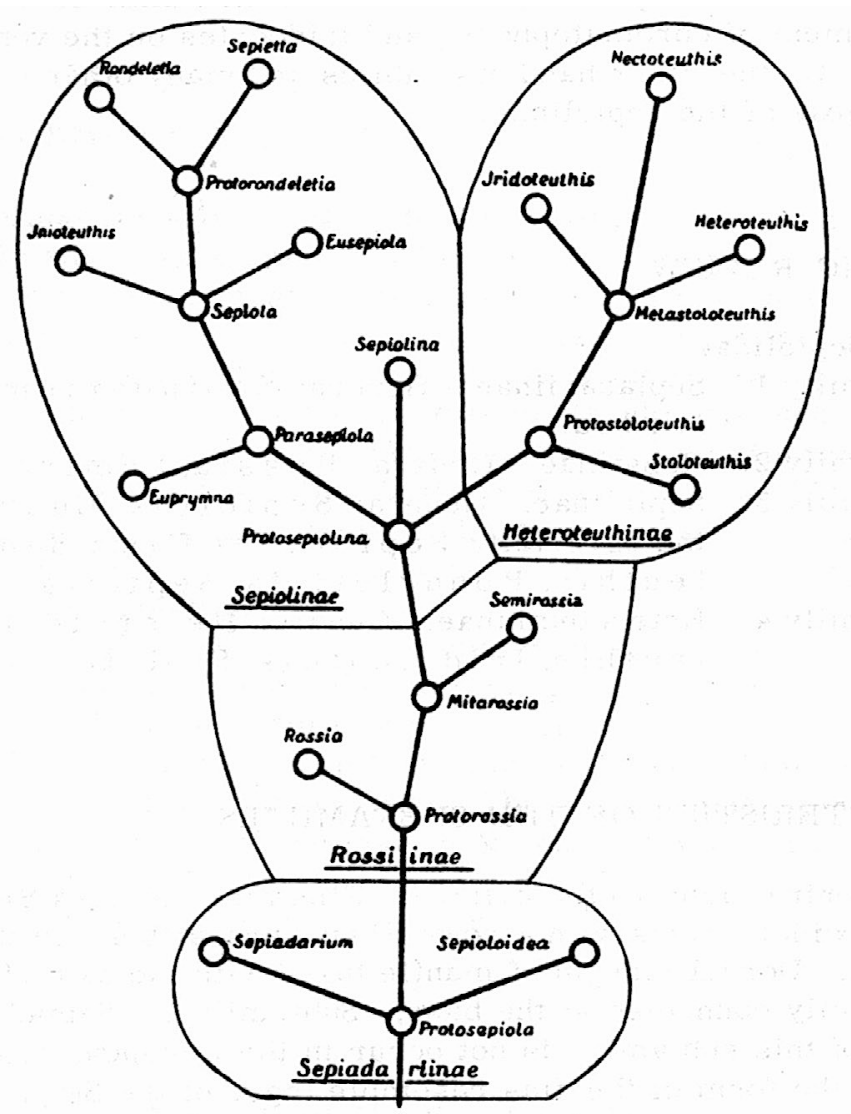

Fig. 5. The 'genealogical tree' of Sepiolidae Leach, 1817 according to Naef (1923: fig. 328). 


\section{Material and methods}

\section{Material examined}

The present work was based on the examination of preserved specimens representative of the diverse basic types of Sepiolinae hectocotyli. The following specimens were loaned from institutional collections or examined on their premises: Rondeletiola minor (Naef, 1912), Sepietta neglecta Naef, 1916, Sepietta obscura Naef, 1916, Sepietta oweniana d'Orbigny, 1841, Sepiola atlantica, Sepiola bursadhaesa Bello, 2013, Sepiola intermedia, Sepiola ligulata and Sepiola rondeletii, males and females (Museo Nacional de Ciencias Naturales, Madrid: the whole Sepiolinae collection as to May 2017); Sepiola boletzkyi Bello \& Salman, 2015 holotype, male, CEP/1994-1, and paratype, female, CEP/1994-2 (Ege Üniversitesi Su Ürünleri Fakültesi Müzesi, Izmir); Inioteuthis maculosa Goodrich, 1896, females, PMBC 11724 (Reference Collection of the Phuket Marine Biology Center); Inioteuthis japonica Verrill, 1881 types, males, YPM IZ 9369 (Yale Peabody Museum of Natural History, New Haven); Euprymna berryi Sasaki, 1929 syntypes, MOL-CEP-247/251/253/277/278/279/280, non-types, MOL-CEP-263/276 (Zoology Collections, University Museum, University of Tokyo); Euprymna morsei (Verrill, 1881), MOLCEP-226/252/284/285 (Zoology Collections, University Museum, University of Tokyo); Euprymna morsei, HUFM-1178 (Hokkaido University Fisheries Museum, Hakodate); Sepiola birostrata, MOL-CEP-264 (Zoology Collections, University Museum, University of Tokyo); Sepiola birostrata, syntypes HUFM-1152A (Hokkaido University Fisheries Museum, Hakodate); Sepiola knudseni Adam, 1984, holotype ZMUC-106 and paratypes ZMUC-108/109/110 (Zoological Museum of the University of Copenhagen).

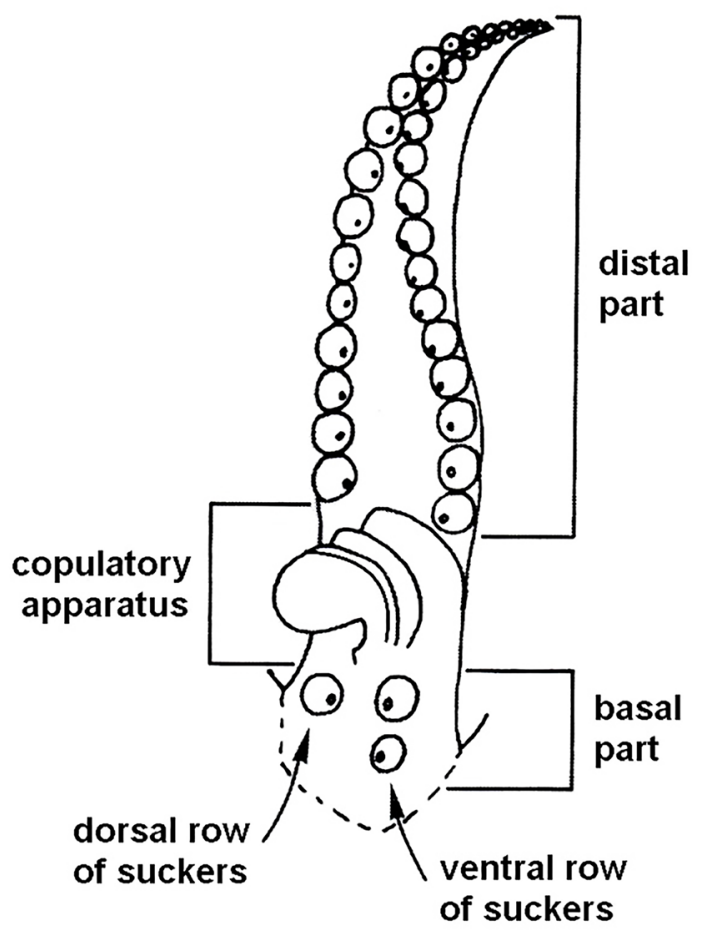

Fig. 6. Schematic drawing of the sepioline hectocotylus. 
Additional specimens of Rondeletiola minor, Sepietta neglecta, Sepietta obscura, Sepietta oweniana, Sepiola intermedia, Sepiola ligulata, Sepiola robusta, Sepiola rondeletii and Sepiola steenstrupiana were from the author's personal collection.

All other species in Sepiolinae were indirectly analysed through the critical reading of both their original descriptions and the available descriptions in handbooks (mainly Reid \& Jereb 2005 and Okutani 2015), reliable internet reports (pages for Cephalopoda in Tree of Life Web Project, edited by Young 19962019) and other pertinent literature.

\section{Terminology}

The three main parts of the sepioline hectocotylus are named (after Naef 1923): 'basal part', 'copulatory apparatus' and 'distal part' (Fig. 6) (see below for details). In the Euprymna-group, the hectocotylus bears highly modified suckers in its distalmost portion, which form a 'palisade' (see below in the Euprymna section) (Fig. 7); this structure is not homologous to the whole distal part as defined above and will be called here palisade or palisaded portion, although it is customarily termed 'distal part' by most authors working on this genus.

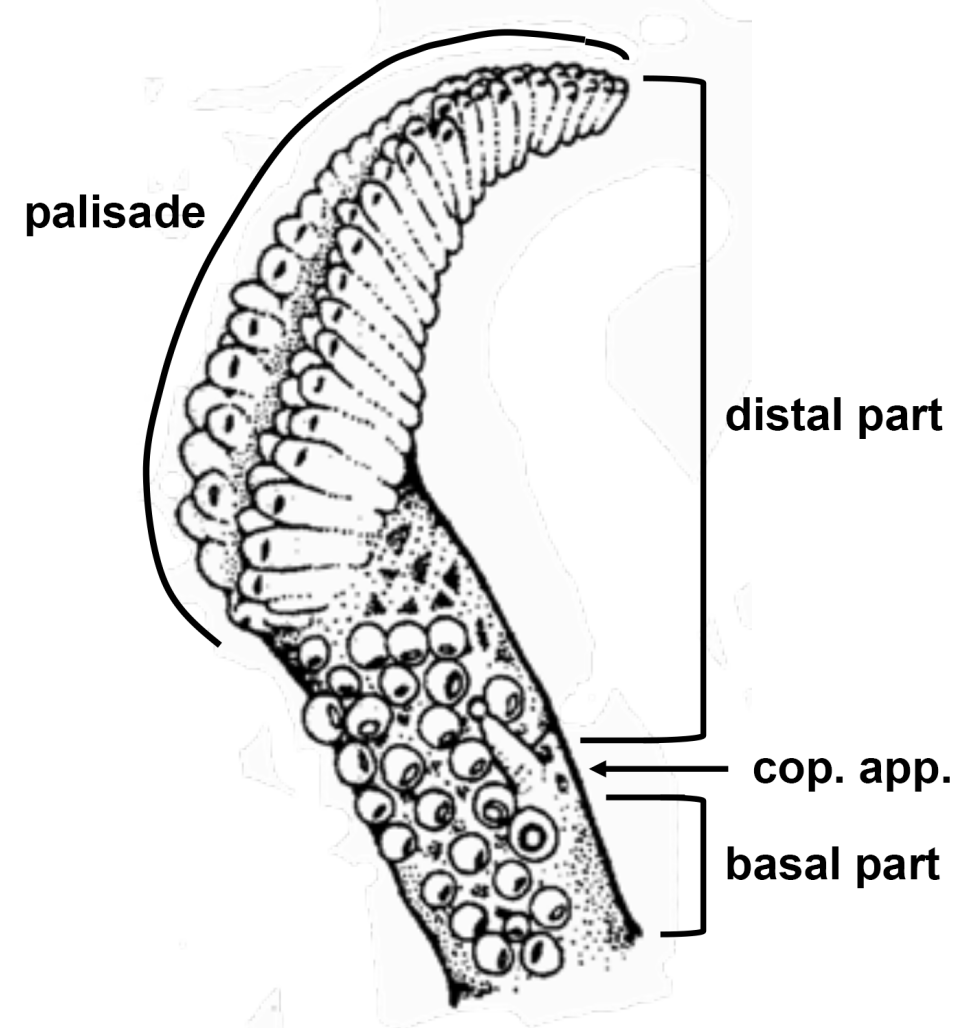

Fig. 7. Schematic drawing of the hectocotylus of Euprymna Steenstrup, 1887. Abbreviations: cop. app. = copulatory apparatus (after Norman \& Lu 1997, modified). 
As for the position of the longitudinal sucker rows on the arm, the term 'dorsal' refers to the row closer to the dorsal midline of the body, and the term 'ventral' to the one on the opposite side of the arm (Fig. 6) (some authors have called the dorsal row 'inner' or 'medial' and the ventral row 'outer' or 'lateral', which may be confusing when writing about sepiolids with four rows of suckers on arms). The sucker pedicels or stalks are preferentially called 'pedicels.'

The two fundamental types of bursa copulatrix by the oviduct outlet are either a pouch with a narrow opening or an uncovered wrinkled area, and are termed 'closed' (Fig. 8A) and 'open' (Fig. 8B), respectively.

In the present paper, the term 'regular' refers to an apparently unmodified structure. Some authors also refer to unmodified structures as 'normal' (e.g., regular or normal arms vs modified arm such as the hectocotylus).

'Biseriate' and 'tetraseriate' arm suckers refer to the occurrence of two and four longitudinal rows of suckers on arms, respectively. The number of longitudinal sucker rows is counted across the centre of arms and tentacle clubs.

Lastly, ML is the abbrevation of mantle length.
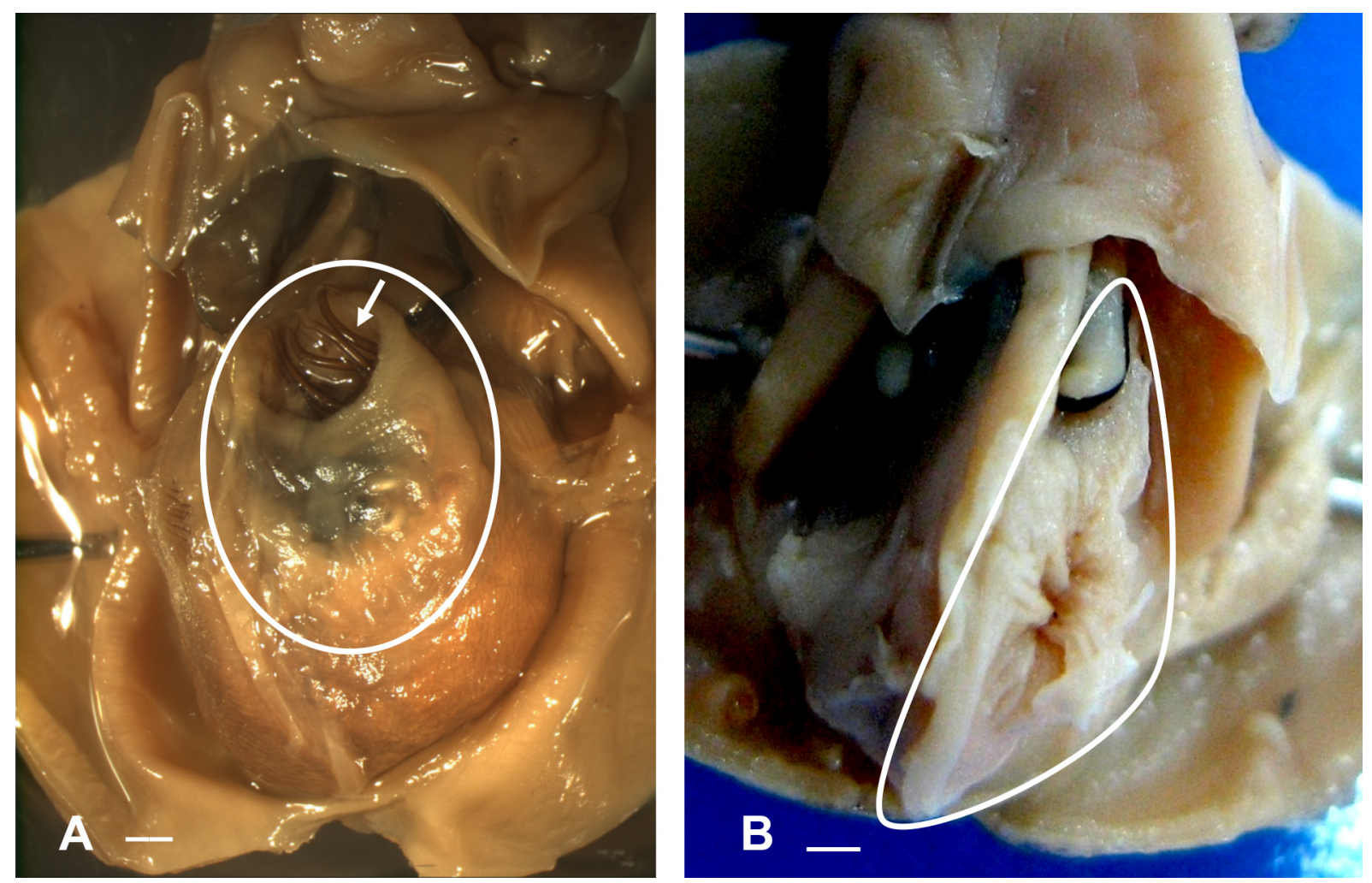

Fig. 8. Basic types of bursae copulatrices in Sepiolinae Leach, 1817 (highlighted by white frames). A. Closed type, plesiomorphic condition; mated female displaying a bunch of spermatophores inserted in the bursa copulatrix and peeping out its opening (arrow) (Sepiola birostrata Sasaki, 1918). B. Open type, apomorphic condition; virgin female (Sepiola boletzkyi Bello \& Salman 2015). Scale bars: $1 \mathrm{~mm}$. 


\section{Results}

\section{Generalities regarding the Sepiolinae hectocotylus}

As mentioned above, the mature hectocotylus (left dorsal arm) of the 'Sepiola-like Eusepiolinae' sensu Naef (1923), i.e., all sepiolines except Euprymna, conforms to a general tripartite Bauplan (structural plan), where the copulatory apparatus marks topographically the separation between the basal and distal sucker groups. The three parts (Fig. 6), from the proximal end of the hectocotylus (arm insertion in the brachial crown) to its distal apex, are:

- the basal part, which consists of few transverse rows of suckers (usually the first two); this is the least modified hectocotylus section; the number of suckers may vary, rarely their size, never their pedicels;

- the copulatory apparatus, in the proximal half of the arm, is formed from conspicuously modified suckerless pedicels, generally in the $3^{\text {rd }}$ and/or $4^{\text {th }}$ transverse sucker row (although in some species additional pedicels may be affected); the pedicels may be elongated and/or widened and flattened, variously curved, and may be fused;

- the distal part is the remaining portion of the arm distal to the copulatory apparatus; its modifications may affect the shape and size of suckers, loss of suckers, shape and size of pedicels, width of the arm oral surface between sucker rows, and mesial lateral side of arm; its general suckered structure is always discernible even when it is greatly modified.

In Euprymna, the hectocotylus tripartite subdivision is not readily apparent and, moreover, the distalmost portion of the arm is uniquely modified into a prominent palisade (see below, the account for Euprymna) (Fig. 7).

\section{Hectocotylus diversity}

Within the general hectocotylian morphological arrangement, species can be grouped according to the nature of the morphological differences they display. These groups may or may not coincide with the genera customarily included in Sepiolinae: Sepiola, Euprymna, Inioteuthis, Rondeletiola and Sepietta. The groups are reported below, broadly ordered according to the degree of development or morphological complexity of their copulatory apparatus. As mentioned above, most modifications affect the copulatory apparatus and the distal part of the hectocotylus. In its simplest expression, the copulatory apparatus consists of one little modified sucker pedicel, i.e., just lengthened and papilla-like, among the suckers of the ventral row.

For each group, the full description of its hectocotylus as well as that of associated non-hectocotylian features are given.

\section{Group A}

Euprymna parva (Sasaki, 1914), Euprymna phenax Voss, 1962 and Euprymna pardalota Reid, 2011.

Description after Voss (1963), Norman \& Lu (1997), Reid (2011 and pers. com.) and Okutani (2015).

\section{Hectocotylus}

Overall MORPHOLOGy (Fig. 9). Hectocotylus approximately equal in size to right arm I; distal tip blunt; leaning or curved aborally; suckers in two rows, as in regular arms; clearly subdivided into two main portions: proximal, which bears regular suckers and one papilla (elongated sucker pedicel), and distalmost with suckers highly modified into palisades; the proximal portion occupies from $1 / 2$ to $2 / 3$ of arm; the palisaded portion the rest of the arm. 
BASAL PART SENSU STRICTO. The part between arm insertion and copulatory apparatus bears two transverse rows of regular suckers.

COPULATORY APPARATUS. Consists of the pedicel of the $3^{\text {rd }}$ sucker of the ventral row modified into elongated and pointed, distally projecting papilla; usually suckerless, it may bear a much-reduced sucker at its tip in E. phenax. The opposite sucker/pedicel element in the $3^{\text {rd }}$ transverse row is regular.

DISTAL PART. Distal to the copulatory apparatus, there is a number (variable according to the species) of regular transverse sucker rows. These are followed by the palisaded portion, that consists of an array of highly modified suckers, which extends to the arm tip; its length extends over $1 / 3$ (E. phenax) to $1 / 2$ of the whole arm (E. parva and E. pardalota). The palisade consists of longitudinally closely packed enlarged columnar sucker pedicels, which terminate in a small opening armed with a toothed horny sucker ring (Reid 2011; Sanchez et al. 2019: fig. 7a); Norman \& Lu (1997) called these elements "columnar suckers". The number of palisades corresponds to that of longitudinal sucker rows. The columnar pedicels are longer than the regular ones, the palisade formation is thus quite prominent.

\section{Additional, non-hectocotylian characters}

Broad ligament between head and mantle; commissure greater than one-third of head width; ventral mantle margin faintly sinuate or with slightly deep funnel indentation. Suckers in 2 longitudinal rows on all arms. Tentacle club suckers in 6 to 14 longitudinal rows. Gladius absent. Visceral light organs: two, paired, each kidney-shaped. The female bursa copulatrix is pouch-like with a small opening through which spermatophores are inserted (closed type bursa copulatrix) (Fig. 8A).

\section{Remarks}

This group includes the species with simplest copulatory apparatus: just one suckerless pedicel in the ventral row simply elongated. According to the available descriptions of the species in this group, the hectocotylus design is rather uniform since its elements vary little across species, apart from the extension of the palisaded portion. Therefore, the hectocotylus alone cannot be used to delineate the member species. The copulatory apparati whose papilla bears a small sucker on its tip probably pertain to not-fully mature males. A similar condition has been observed in a few specimens of Sepiola birostrata (see below). Euprymna parva, which was removed from Sepiola by Sanchez et al. (2019), is placed into

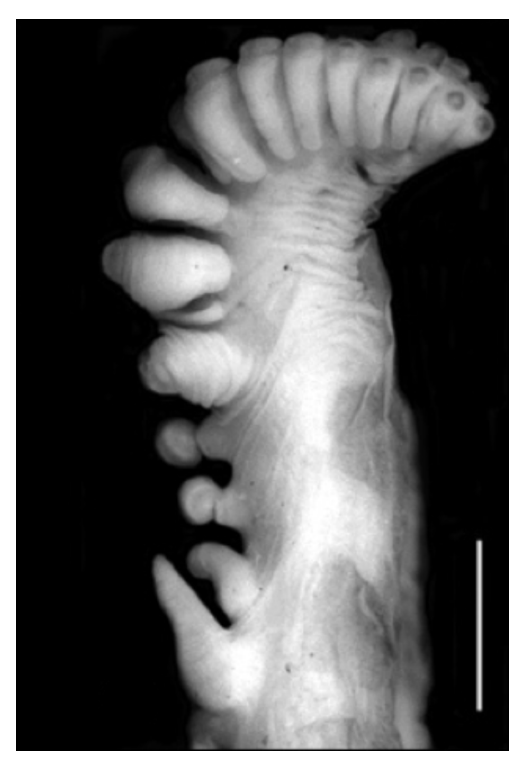

Fig. 9. Hectocotylus of Euprymna pardalota Reid, 2011 lateral view. Scale bar: 1 mm (after Reid 2011). 
this group because of its similarity to E. pardalota and E. phenax (Reid, pers. com.). It has also been observed that the tentacular club suckers of both parva and pardalota have a 'brushlike' ultrastructure (Takayama \& Okutani 1992: fig. 6; Reid 2011: fig. 4D). This is yet to be examined in E. phenax and all nominal Euprymna to determine whether this may be another diagnostic trait for this clade.

\section{Group B}

This group includes all species of Euprymna except E. phenax, E. pardalota and E. parva. Hence, it includes: E. stenodactyla (Grant, 1833), E. penares (Gray, 1849), E. morsei, E. tasmanica (Pfeffer, 1884), E. scolopes Berry, 1913, E. berryi, E. albatrossae Voss, 1962, E. hoylei Adam, 1986, E. hyllebergi, Nateewathana, 1997, E. megaspadicea Kubodera \& Okutani, 2002 (MolluscaBase 2018a); to these species, the recently discovered and described E. brenneri Sanchez et al., 2019 is to be added. Some other nominal species are not considered here because of their unresolved status (cf. Norman \& Lu 1997).

Description after Voss (1963), Okutani \& Horita (1987), Norman \& Lu (1997), Nateewathana (1997), Kubodera \& Okutani (2002), author's pers. obs.

\section{Hectocotylus}

Overall MORPHOLOGY (Fig. 7). Hectocotylus either shorter or equal-sized or longer than right arm I; thicker than right arm I; blunt-pointed; leaning or curved aborally; number of sucker rows as in regular arms; clearly subdivided into two main portions: proximal, which bears regular suckers and few papillae (elongate sucker pedicels, see next below), and distalmost, with suckers highly modified into palisades (see below). The proximal portion occupies from $1 / 5$ (E. megaspadicea) to $1 / 2$ of arm (the latter in most cases); the distalmost palisaded portion occupies the rest of the arm.

BASAL PART SENSU STRICTO. The part between the arm insertion and copulatory apparatus bears two ( 2 or 3 in E. tasmanica) transverse rows of regular suckers.

Copulatory apparatus. Consists of 1-3 pedicels of the ventral sucker row modified into papillae, i.e., elongate and pointed distally projecting structures, suckerless in most species; in E. tasmanica the papillae may bear a much-reduced sucker at their tips. The first or most proximal papilla is the modified pedicel of the $3^{\text {rd }}$ ventral sucker in most cases. The number of papillae varies according to the species and may vary within the same species (1-2 in E. berryi, E. hyllebergi, E. megaspadicea, E. morsei, E. tasmanica; 2 in E. albatrossae; 3 in E. hoylei). When there is more than one papilla, they are completely separate, i.e., not fused with each other, even at their bases. All other sucker/pedicel elements in the transverse rows containing the papillae are regular.

DistAl PART. Distal to the copulatory apparatus, there is a number, variable according to the species, of regular transverse sucker rows. Further distally, there is the palisaded portion, consisting of an array of highly modified suckers that extends to the arm tip. Its length extends for $1 / 2$ (most species) to $4 / 5$ (E. megaspadicea) of the whole arm. As in the hectocotylus of Group A, the palisade consists of longitudinally closely packed enlarged columnar sucker pedicels, which terminate distally in a small opening armed with a toothed horny sucker ring (columnar suckers of Norman \& Lu 1997). The latter authors showed that each minute sucker is partially covered by a fleshy cap; other authors report "a slitlike aperture, with fleshy lips" (Voss, 1963: 50, about E. albatrossae) or, simply, a slit-like opening (e.g., Nateewathana 1997 about $E$. hyllebergi); in other cases, no detailed description of this trait is given. The number of palisades corresponds to that of longitudinal sucker rows, i.e., four, at least proximally, and reduces to two towards the tip of the hectocotylus, where the columnar pedicels are more appressed to one another. In E. megaspadicea, there are apparently only three palisade rows instead of four, seemingly because the columnar pedicels of the two ventral rows are positioned in just one wavy line (Kubodera \& 
Okutani 2002). In general, the elements of the ventral palisades, hence the palisades themselves, are larger than the dorsal ones. In E. morsei at least, the columnar pedicels of the ventral row are joined to each other by a membrane (author's pers. obs.). The ventral palisades are usually separated from the dorsal ones by a space in between, varying in width according to the species and stage of maturity. Since the columnar pedicels are longer than the regular ones, the palisade formation is quite prominent.

\section{Additional, non-hectocotylian characters}

Broad ligament between head and mantle; commissure greater than one-third of head width; ventral mantle margin slightly sinuate. Suckers in 4 (exceptionally 8 ) longitudinal rows on all arms; in mature males, enlargement of suckers in marginal longitudinal rows of some regular arms also occurs (Norman \& Lu 1997). Tentacle club with numerous minute suckers in a few tens of longitudinal rows. Gladius absent. Visceral light organs: two, paired, each kidney-shaped. The female bursa copulatrix is pouchlike with a small opening through which spermatophores are inserted (closed type bursa copulatrix); in E. morsei and E. berryi, at least, the cover of the bursa copulatrix adheres to the mantle, so that, when cutting and folding up the mantle to expose its cavity organs, the cover tears apart (author's pers. obs.).

\section{Remarks}

The copulatory apparatus of this group of species, as in Group A, is very simple, comprising 1-3 papillae, in the ventral row only. Their palisade differs from that of Group A in possessing fleshy distal caps.

Except for E. megaspadicea (the only known comparatively deep-water species in the group) the hectocotylus design is rather uniform; its elements vary little among species. Therefore, the hectocotylus alone cannot be used to discriminate among species in the group and so additional characters must be considered (Norman \& Lu 1997).

The copulatory apparati whose papillae bear a small sucker on their tip possibly pertain to not-fully mature males. A similar condition has been observed in a few specimens of Sepiola birostrata (see below) (author's pers. obs.).

\section{Group C}

Sepiola knudseni Adam, 1984.

Description after Adam (1984) and author's personal observations of the types.

\section{Hectocotylus}

Overall MORPHOLOGY (Fig. 10A). Hectocotylus longer and thicker than right arm I; curved dorsolaterally; apex blunt; suckers in two rows, as in regular arms. Moderately broad between sucker rows in both copulatory apparatus zone and distal part.

BASAL PART. According to Adam (1984: 158), proximal to the copulatory apparatus there is "a single (perhaps more) small sucker." The situation, however, is not perfectly clear because in order to keep valuable type specimens intact it is not possible to remove the hectocotylus from the type specimens to examine this closely. The nearly mature hectocotylus appears to have a single sucker in the ventral row, slightly displaced toward the middle of the arm and aligned with the ventral modified pedicels of the copulatory apparatus; in later stages of maturity, this sucker is further displaced towards the midline of the arm, close to both the proximo-ventral modified pedicel of the copulatory apparatus and the corresponding dorsal sucker.

COPULATORY APPARATUS. Only the sucker/pedicel elements of the ventral row are modified. Three ventral suckerless pedicels are enlarged and lengthened into thick, bluntly-pointed horns; the basal-most one the smallest. In the more developed hectocotylus of the more mature animal, the three horns are fused 
to each other into a single formation, which is also visible from the aboral, or outer side of the arm (Fig. 10B). The opposing suckers in the dorsal row are regular, widely spaced from the modified ventral pedicels.

DistAL PART. Four enlarged suckers in the middle of the dorsal row. Ventral sucker row devoid of sucker/ pedicel elements in proximal $2 / 3$, remains of reduced pedicels barely visible (in not fully mature hectocotyli, suckers are missing and pedicels are partly reduced); distal $1 / 3$ of ventral row bears 8 suckers smaller than those in opposing dorsal row. Dorsal and ventral sucker rows widely spaced throughout their length.

\section{Additional, non hectocotylian characters}

Ventral mantle margin slightly sinuate, without any deep funnel indentation (Adam 1984). Fins rounded, their length about one half of mantle length. Arms of third pair thicker than the others, arms of fourth pair shortest and weakest (author's pers. obs.). Tentacular clubs with suckers in 8 longitudinal rows, some of dorsal-most row larger (Adam 1984). Visceral unpaired light organ cordiform (i.e., heartshaped), deriving from the fusion of two paired light organs; it is slightly longer than wide, posterior extremity bluntly rounded and anteriorly bilobed (Fig. 11), each lobe recalls the anterior lobe of the paired kidney-shaped light organs of Euprymna and Sepiola (author's pers. obs.). Smallest sized species
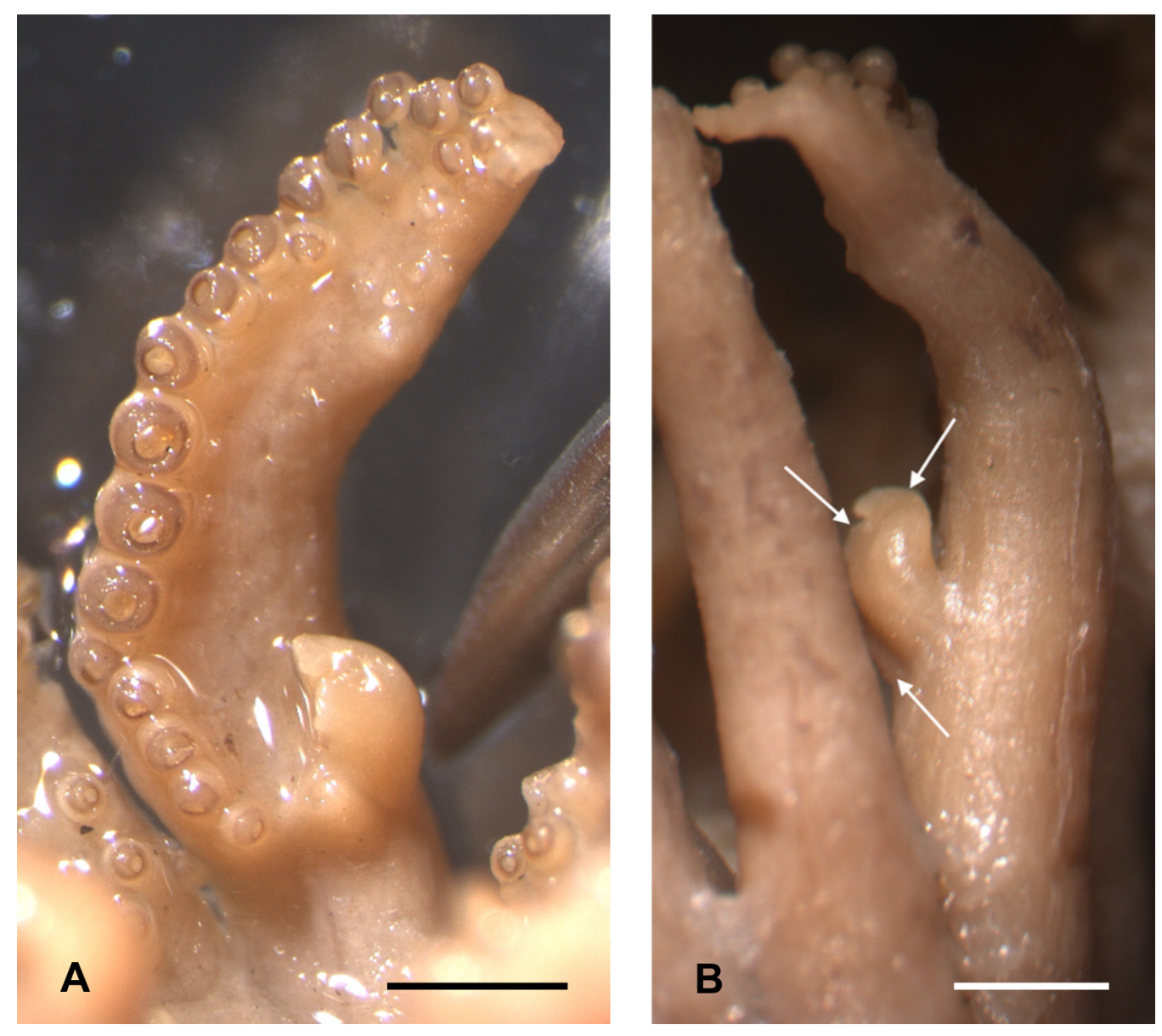

Fig. 10. Hectocotylus of Sepiola knudseni Adam, 1984. A. Oral view. B. Dorsal view; the arrows point to the three modified ventral sucker pedicels. Scale bars: $1 \mathrm{~mm}$. 
in Sepiolinae (largest examined mature male and female: 8.5 and $9.0 \mathrm{~mm}$ ML, respectively). The female bursa copulatrix is pouch-like with a wide opening through which spermatophores are inserted (closed type bursa copulatrix). The presence/absence of a gladius was not ascertained by the present author to avoid dissecting the types, nor was it reported by Adam (1984).

\section{Remarks}

The copulatory apparatus of the hectocotylus of $S$. knudseni is formed from modified suckerless pedicels in the ventral row only, as the one in species in Groups A and B; however, its modified pedicels are morphologically different from those of the latter species and represent a further modification with respect to them. Moreover, the peculiar cordiform light organ of S. knudseni ("bilobed" according to Adam [1984: 159]) clearly shows that this species does not belong either in the genus Sepiola or in Euprymna (as currently understood), which are both characterized (by definition) by a pair of kidney-shaped light organs (e.g., Reid \& Jereb 2005). The cordiform light organ also differs from that of Rondeletiola minor, whose outline is quite round without any anterior lobes and posterior feeble protrusion (see below). The morphology of the sepiolid visceral light organs has systematic significance: according to Nishiguchi et al. (2004) the unpaired light organ occurring in some sepiolid taxa (Heteroteuthis Gray, 1849, Stoloteuthis Verrill, 1881, Sepiolina Naef, 1912, Rondeletiola and Semirossia Steenstrup, 1887) represents an intermediate state in the evolution of the light organ towards the two kidney-shaped lobed organs. Sepiola knudseni falls in that group, although its unpaired light organ has a shape different from round, which deserves further investigation. In addition, the copulatory apparatus of the hectocotylus of $S$. knudseni diverges from that of R. minor as well as all other species of Sepiola because no sucker pedicels in the dorsal row are modified. The number of longitudinal rows of suckers on the tentacle club also separates $S$. knudseni from $R$. minor, since they bear 8 and 16 rows respectively. The bursa copulatrix of the species in this group, though being of the closed type, differs from all other closed bursae copulatrices because of its wide opening and, obviously, it also diverges from that of $R$. minor, which is open (see below). Adam (1984: 159) described the bursa copulatrix of $S$. knudseni as circular, smaller than that of "Mediterranean species described by Naef (1923)", but it appears that he referred just to the bursa copulatrix opening. These peculiarities keep $S$. knudseni apart from all known genera in Sepiolinae and firmly supports the need to place it in its own genus.

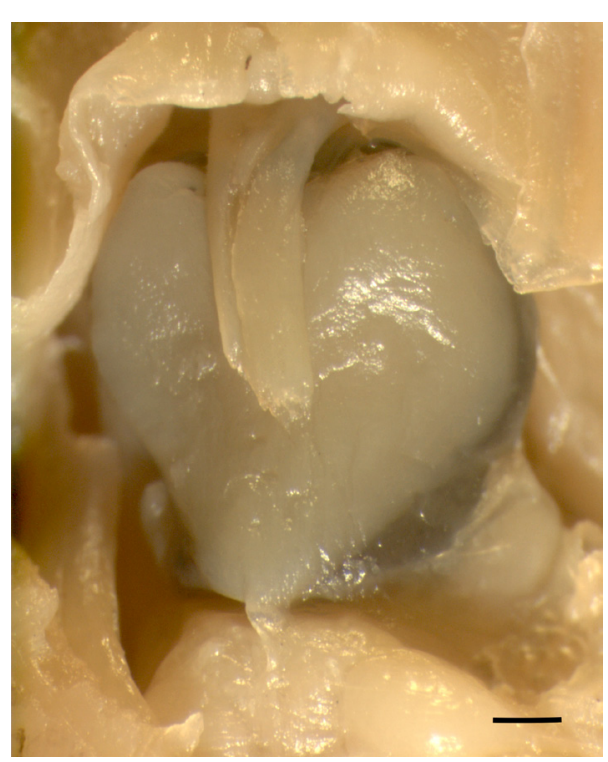

Fig. 11. Visceral light organ of Sepiola knudseni Adam, 1984. Scale bar: $1 \mathrm{~mm}$. 


\section{Group D}

Genus Inioteuthis: I. japonica and I. maculosa (cf. Young \& Vecchione 2004). Other sources (e.g., Sweeney 2001; Reid \& Jereb 2005; MolluscaBase 2018b) include I. capensis Voss, 1962; however, capensis does not appear to belong to Inioteuthis (see below Group H).

Description after author's personal observations of I. japonica; some details after literature.

\section{Hectocotylus}

Overall MORPHOLOGY (Fig. 12). Hectocotylus either equal sized or shorter than right arm I (Okutani 2015) with tapering tip; suckers in two rows, as in regular arms; broadly enlarged in the proximal half, because of ear-like copulatory apparatus, regular in the distal half.

BASAL PART. Two transverse rows, the first with regular suckers, the second with only the ventral sucker, much reduced (three suckers, in all).

Copulatory apparatus. Proximal half of arm modified; this is broadly enlarged because of a large, prominent, ear-like structure on the arm oral face (also noticeable in lateral and aboral view). Several sucker pedicels from both the ventral and dorsal rows contribute to form the copulatory apparatus. The transformed ventral row of suckers consists of two complex structures ("lobes" in Voss 1963), proximal and distal respectively, separated by a space ("median notch" in Voss 1963) where a low crest runs longitudinally (see below). The proximo-ventral structure is formed from three suckerless pedicels (sucker nos. 3, 4 and 5 of overall arm ventral row, counting from proximal to distal end of the arm) enlarged and curved horn-like, the first smallest; the horns are joined by a narrow web, the first two
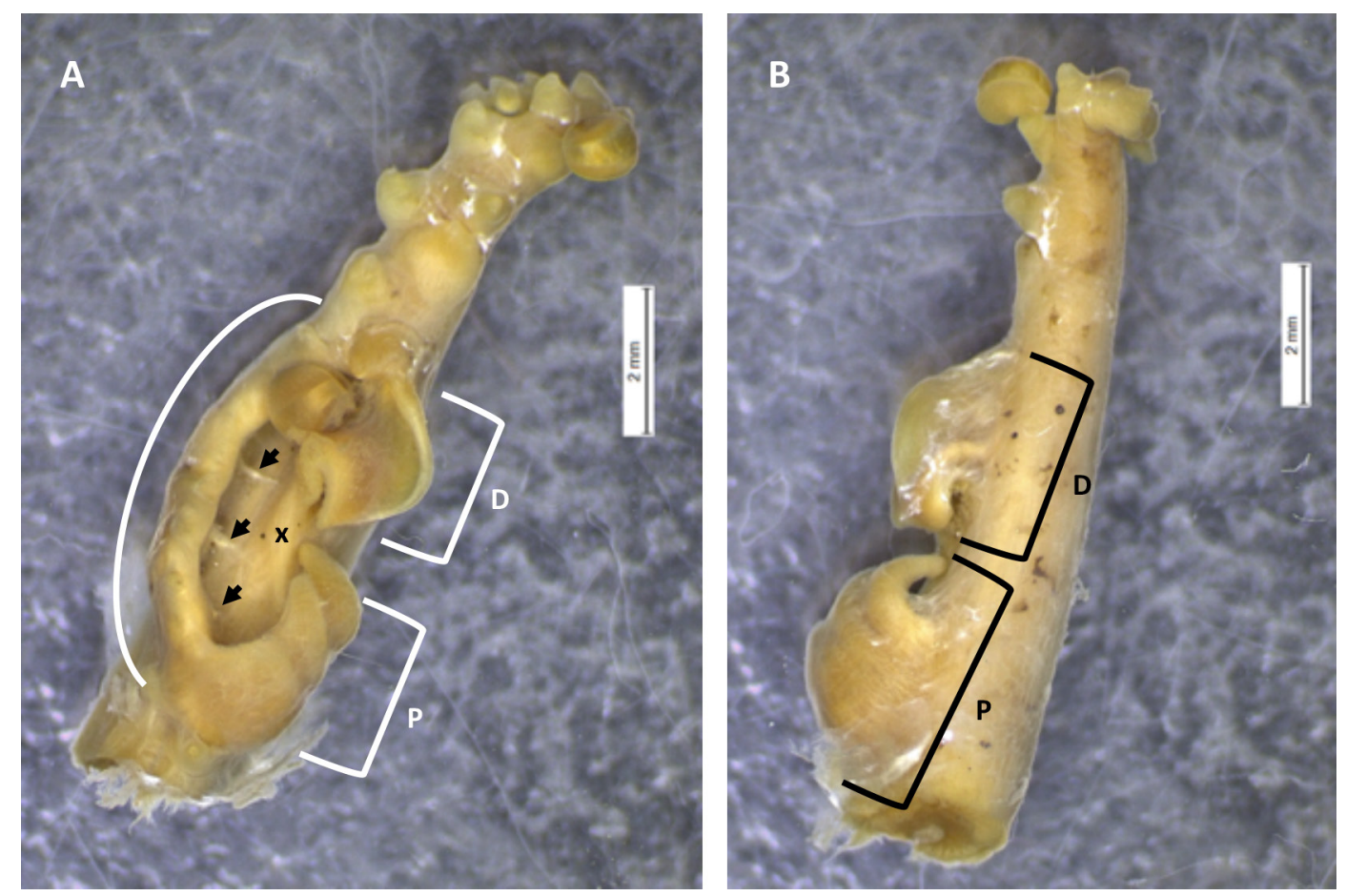

Fig. 12. Hectocotylus of Inioteuthis japonica Verrill, 1881. A. Oral view. B. Lateral view. The brackets $P$ and D comprise the proximal and distal structures of the copulatory apparatus ventral side, respectively; an X marks the longitudinal crest between the two structures. The curved line embraces the swollen dorsal margin of the copulatory apparatus, whose modified pedicels (indicated by arrows) look like trabeculae holding the joining web. Scale bars: $2 \mathrm{~mm}$. 
throughout their length, the second and the third only at their bases, so that the third horn is distally free and very curved. The distal structure of the ventral side of the copulatory apparatus appears to be derived from considerable modification of about four pedicels that are transformed into laminae fused with each other to form a shallow trough where a very large sucker, the first of the ventral row of the distal part, lies; only the first of these four pedicels ( $6^{\text {th }}$ of overall arm ventral row), though contributing to the formation of the trough, conserves a hint of the original pedicel-like appearance and displays at its tip (in the proximal margin of the trough) a hollow where likely its totally reduced sucker once sat; from this modified pedicel, the above mentioned longitudinal low crest extends to the base of the middle horn-like pedicel of the proximal structure. The swollen dorsal margin of the copulatory apparatus is formed from six considerably lengthened pedicels that are curved ventrally and are conjoined by a broad web, thus forming a rounded ridge; the web runs all along the dorsal margin of the arm and, proximally, to the first horn-like pedicel of the ventral row; hence, this webbed elevated structure (vaguely resembling the helix in the human right ear) continues from the middle ventral side to the whole dorsal side of the copulatory apparatus, giving the impression that the arm oral surface is excavated (see below in Remarks); some modified dorsal pedicels bear a tiny sucker at their tip.

DiSTAL PART. Tapering to the arm tip; first ventral sucker very large, laying on the trough-like structure of the copulatory apparatus; all other ventral suckers enlarged to a lesser extent; suckers in the dorsal row regular.

\section{Additional, non-hectocotylian characters}

Commissure of the mantle-head ligament one third of the head width or smaller. Arm suckers biseriate, larger in males than in females; tentacular club with suckers in 8-10 longitudinal rows; gladius absent; light organs absent (Verrill 1881; Voss 1963; Nateewathana 1997; author's pers. obs.). The female bursa copulatrix is pouch-like with a small opening through which spermatophores are inserted (closed type bursa copulatrix) (author's pers. obs.).

\section{Remarks}

In Inioteuthis, the hectocotylus has a wide and composite copulatory apparatus where the modified ventral pedicels, in two separate and diverse groups, are the most numerous in any species of Sepiolinae, and several dorsal pedicels, with heavily or totally reduced suckers, are just slightly elongated, curved inward and joined by a web. Apart from the web, this is the simplest modification of dorsal sucker/ pedicel elements of the copulatory apparatus in any Sepiolinae. In contrast to the hectocotylus modified portion, the distal part of the arm is quite regular, the only modifications concern the enlargement of a few suckers in the ventral row.

Voss (1963) and Nateewathana (1997), respectively, call "basal half" and "basal part" the proximal modified portion of the arm, which is in fact the true basal part + the copulatory apparatus. No fully satisfactory description of the hectocotylus is available in the literature (e.g., Verrill 1881; Sasaki 1929; Voss 1963; Nateewathana 1997) and, in fact, some discrepancies among those descriptions are caused by their incompleteness (compare for instance Verrill (1881) with Sasaki (1929) on I. japonica and Voss (1963) with Nateewathana (1997) on I. maculosa). Indeed, the true nature of the copulatory apparatus has been overlooked; its structure is elaborate, formed in both its ventral and dorsal parts by modified pedicels, some of them to a great extent. In this respect the examination of maturing hectocotyli is of great help, as is usual with sepioline hectocotyli. The "deep excavation" of the arm oral surface mentioned by Voss (1963) and Nateewathana (1997) is not an actual excavation but rather an apparent depression caused by the conspicuous elevation of the helix-like structure in the copulatory apparatus with respect to the arm oral face. 
To the best of my knowledge, no description of the bursa copulatrix of Inioteuthis is available in the literature; hence that reported in the above paragraph "Additional, non-hectocotylian characters" is the first account of it.

Some reference works (e.g., Sweeney 2001; Reid \& Jereb 2005; MolluscaBase 2018b) indicate Sepiola japonica Tilesius in d'Orbigny, 1845 (or Sepiola japonica d'Orbigny, 1845) as type species of this genus, but this is a nomen dubium (Gleadall \& Bello, pers. obs.).

As for the species I. capensis, it is quite evident that it does not belong to Inioteuthis because of the very different hectocotylus and the presence in its mantle cavity of a conspicuous light organ (see also Young \& Vecchione 2004).

\section{Group E}

Sepiola birostrata and Sepiola trirostrata.

Description after author's personal observations of 20 paratypes of S. birostrata.

\section{Hectocotylus}

Overall MORPHOLOGY (Fig. 13A). Hectocotylus about $3 / 4$ the length of the right arm I and about $55 \%$ of ML. In about $1 / 3$ of the preserved specimens examined, the distal part axis rotated towards the right arm I more than $1 / 4$ of turn with respect to the arm proximal part; in some specimens it is straight, in others bent aborally. Apex blunt. Suckers in 2 rows, as in regular arms. In dorsal view, the distal part is widened in the middle because of the enlarged sucker pedicels (see 'Distal part', below).

BASAL PART. Four regular suckers in two rows.

COPULATORY APPARATUS. Its formation involves the $3^{\text {rd }}$ and $4^{\text {th }}$ suckerless pedicels of both the ventral and dorsal rows. Third and $4^{\text {th }}$ ventral pedicels modified into curved, horn-like pointed processes (the 'rostra' of the specific name), aligned, directed distally and slightly laterally (in several specimens visible in animal dorsal view); proximal-most process ( $3^{\text {rd }}$ ventral pedicel) smaller and less curved than distal ( $4^{\text {th }}$ ventral pedicel). Third and $4^{\text {th }}$ dorsal pedicels flattened and directed ventrally, fused with each other and to the oral arm surface as well as with the base of both ventral horns, to form a concave pad.

DisTAL PART. First two sucker/pedicel elements of ventral row completely reduced, making space for the distal horn of the copulatory apparatus. First three suckers of dorsal row absent, their pedicels modified into low transverse ridges, narrowly spaced, the first barely visible. Following pedicels of both rows leaf-like, lengthened, widened and flattened promixo-distally, either triangular- (in most cases) or squarish-shaped, their bases inserted transversally on the arm oral surface and their external border slightly thicker, the pedicels of the two rows alternating in a zig-zag pattern, so that, within each row, the suckers are not longitudinally aligned but also displaced in zig-zag arrangement. Distalmost 6-7 suckers of both rows with short, regular (non-flattened) pedicels. In all, 22-23 suckers in dorsal row of distal part. In fully mature hectocotyli, distal part enlarged, with sucker/pedicel elements visible in aboral view of arm. In several specimens, either or both ventral and dorsal protective margins of the first $1 / 3$ of distal part as a line of tiny vestigial suckers and pedicels (Fig. 13B). In many specimens an aboral keel is visible in the distal third of arm. In about $1 / 3$ of specimens, arm distal part rotated by about $1 / 4$ of turn with respect to proximal part, thus facing the right dorsal arm.

\section{Additional, non-hectocotylian characters}

Gladius absent. Mantle ventral margin very slightly undulate or straight, barely notched at funnel. Fins long with anterior broad, round lobe almost reaching the mantle border and posterior margin straight without lobe. Tentacle club not enlarged, with about 8 rows of minute, equal-sized suckers. The female 
bursa copulatrix is pouch-like with a small opening through which spermatophores are inserted (closed type bursa copulatrix) (author's pers. obs.) (Fig. 8A).

\section{Remarks}

The main features of the $S$. birostrata hectocotylus are the quite primitive shape (with respect to the other sepiolines except Euprymna) of the ventral pedicels of the copulatory apparatus, greatly modified dorsal pedicels of the same apparatus and very greatly and uniquely modified pedicels of the distal part.

In order to appreciate the structure of the copulatory apparatus, it is necessary to observe its ontogenetic development. In fact, the presence in a specimen $(\mathrm{ML}=16.5 \mathrm{~mm})$ of a small sucker at the tip of the proximal ventral horn is further evidence that horns originate from modified sucker pedicels. As for the ontogeny of the copulatory apparatus pad from the $3^{\text {rd }}$ and $4^{\text {th }}$ highly modified dorsal pedicels, the $3^{\text {rd }}$ pedicel may bear, in not fully mature hectocotyli, a residual sucker by the base of the proximal ventral horn; moreover, the rim of those flattened dorsal pedicels is evident where they fuse with the ventral horns.

In this species, the copulatory arm displays a very high degree of variability, unprecedented among members of Sepiolinae (Takayama \& Okutani 1992; author's pers. obs.). Moreover, despite the fact that all of the 20 male specimens examined by me (ML range $=15.0-20.5 \mathrm{~mm}$ ) were sexually mature (i.e., they contained fully developed spermatophores), their hectocotyli showed different degrees of development, and, therefore, maturity in all their parts.

The rows of vestigial suckers positioned laterally to the ventral row of suckers and mesially to the dorsal one, respectively, as well as the occurrence of tiny papillae at the base of the ventral horns, ventrally to them, are, in my opinion, the much-reduced remains of two additional rows of suckers; in other words, an atavism.
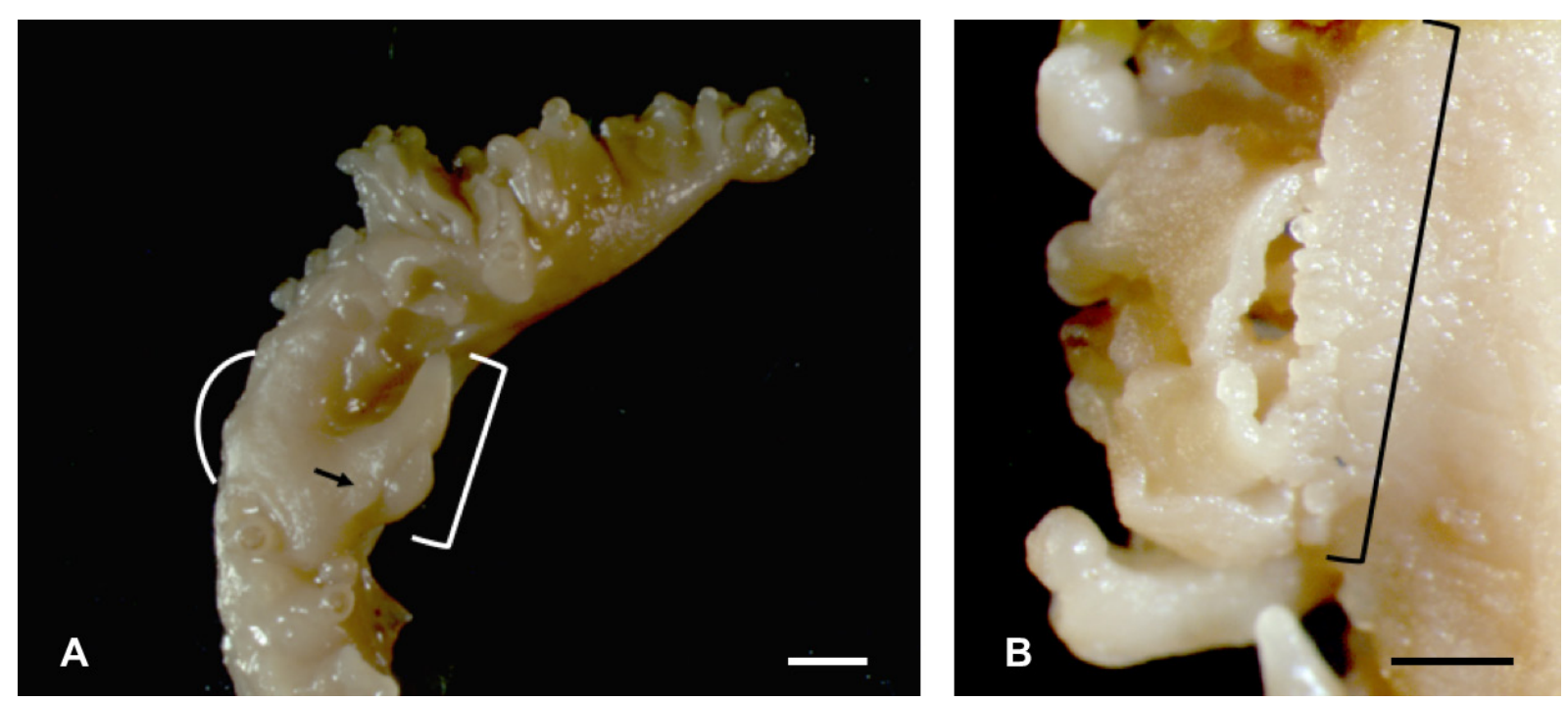

Fig. 13. Hectocotylus of Sepiola birostrata Sasaki, 1918. A. The square bracket indicates the two hornlike modified ventral pedicels of the copulatory apparatus; the curved line encompasses the flattened modified dorsal pedicels of the copulatory apparatus and the arrow points at the hollow left by a reduced sucker. In the distal part, several leafy pedicels bearing regular suckers are visible. B. Detail of the ventral row of vestigial suckers, encompassed by the square bracket; below it, the point of the copulatory apparatus distal horn is visible; to the left side, several leaf-like pedicels of the distal part are evident. Scale bars: $\mathrm{A}=1 \mathrm{~mm} ; \mathrm{B}=0.5 \mathrm{~mm}$. 
The distinctive sucker pedicels in the hectocotylus distal part are remarkably different from the columnar pedicels of the Euprymna palisades. In S. birostrata the pedicels are broad at their insertion on the arm and taper to a small apex, smaller than the regular suckers attached to them, whereas in Euprymna the pedicel bases are as broad as their distal tips, where highly reduced suckers are embedded. However, the S. birostrata bursa copulatrix is of the closed type as in Euprymna.

The other nominal East Asian species of Sepiola, namely trirostrata, is reportedly closely related to birostrata, from which it may be separated by its copulatory apparatus morphology: with three 'rostra', i.e., the horn-like pedicels, in trirostrata instead of two as in birostrata (Reid \& Jereb 2005; Okutani 2015). A closer re-reading of the description of S. trirostrata in Voss (1963) discloses that its 'accessory knob' (the 'third rostrum'), placed mesially to the ventral horns, derives, in fact, from modified pedicel(s) of the dorsal sucker row (cf. also Takayama \& Okutani 1992: fig. 12), which condition gives ground for associating this species with $S$. birostrata. In contrast, the lack of modified dorsal sucker pedicels in the copulatory apparatus of E. parva (formerly in Sepiola) - its solitary horn derived from the $3^{\text {rd }}$ sucker of the ventral row - further shows that this species does not fit in the same group with birostrata and trirostrata. Additional characters, such as the chitinous ring of tentacular suckers, corroborate this hypothesis (Takayama \& Okutani 1992). These facts support the decision by Sanchez et al. (2019) to remove parva from Sepiola and place it in the genus Euprymna; its biseriate sucker arrangement places it in Group A of the present paper (see above).

\section{Group F}

Sepiola ligulata

Description after Naef, 1923 and author's personal observations.

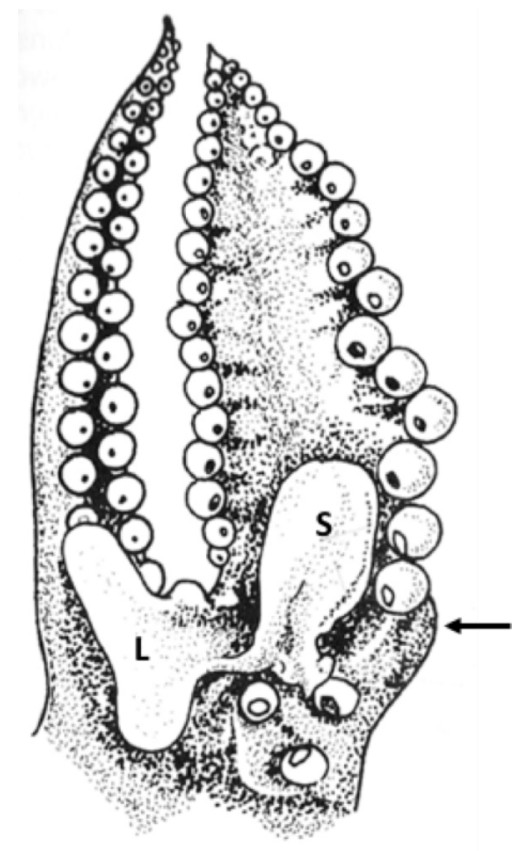

Fig. 14. Pair of dorsal arms of Sepiola ligulata Naef, 1912; the hectocotylus is on the right-hand side. The arrow points at the horn-like modified $4^{\text {th }}$ ventral pedicel in the copulatory apparatus ("main tooth" of Naef 1923); its point is not visible because hidden by the first ventral sucker of distal part; the $3^{\text {rd }}$ ventral pedicel too, at the base of $4^{\text {th }}$, is barely visible in this drawing. Abbreviations: $\mathrm{S}=$ spatula-like lobe in the copulatory apparatus, formed by $2^{\text {nd }}$ and $3^{\text {rd }}$ modified dorsal pedicels; $\mathrm{L}=$ 'ligula', the shovellike lobe formed by $4^{\text {th }}$ to $5-6^{\text {th }}$ dorsal pedicels (after Naef 1923 , modified). 


\section{Hectocotylus}

Overall MORPHOLOGY (Fig. 14). Hectocotylus shorter than first right arm. Apex blunt. Suckers in 2 rows, as in regular arms. Markedly broad in the distal part.

BASAL PART. One transverse row of suckers followed by single sucker in ventral row (in all, 3 suckers: 2 ventral and 1 dorsal).

Copulatory apparatus. Several suckerless pedicels contribute to its formation: $3^{\text {rd }}$ and $4^{\text {th }}$ pedicels of ventral row and $2^{\text {nd }}$ to $5^{\text {th }}$ or $6^{\text {th }}$ pedicels of dorsal row. Ventral-most pedicel ( $4^{\text {th }}$ of ventral row $)$ horn-like, curved and pointed, distally directed ('main tooth'); $3^{\text {rd }}$ ventral pedicel, a reduced tubercle at the base of main tooth; mesially to the latter a spatula-like lobe, formed by the lengthwise fusion of elongated $2^{\text {nd }}$ and $3^{\text {rd }}$ dorsal pedicels, distally directed, lodged in the widened part of arm oral surface (see below); adjacent to spatula-like lobe, a stalked shovel-like appendage ('ligula') derived from next 2-3 dorsal row pedicels $\left(4^{\text {th }}\right.$ to $\left.5-6^{\text {th }}\right)$, projecting toward right arm, with two small tubercles (probable rudimentary pedicels) on distal edge of shovel stalk.

Distal PART. Suckers of ventral row slightly enlarged; pedicels of both rows slightly lengthened; oral surface between sucker rows very broad, almost to the distal arm tip, spoon-like.

\section{Additional, non-hectocotylian characters}

Deep funnel indentation and ventral mantle protruding anteriorly on each side of the funnel to form a markedly sinuate margin. Gladius present as a distinct rudiment. Tentacular clubs with suckers in 8 longitudinal rows. Female bursa copulatrix in left ventral part of mantle cavity with a large caecum in the right side of mantle cavity, not enclosed in a pouch, with noticeable folds converging towards its centre (open type bursa copulatrix).

\section{Remarks}

Sepiola ligulata is unique among the nominal species of Sepiola because of its elaborate hectocotylus and the corresponding wide bursa copulatrix with a large caecum. In the copulatory apparatus, the highly modified ligula-like and spatula-like formations derived from the dorsal sucker row coexist with the rather primitive horn-like ventral pedicels, which are somewhat similar to those in S. birostrata. Another primitive feature is the separate condition of the modified ventral pedicels, neither fused with each other nor to the dorsal pedicels.

\section{Group G}

Sepiola aurantiaca and Sepiola pfefferi Grimpe, 1921.

Description after Jatta (1896), Naef (1923) and Goud \& de Heij (2012).

\section{Hectocotylus}

Overall MORPHOLOGY (Fig. 15). Hectocotylus shorter than first right arm, straight. Apex blunt. Suckers in 2 rows, as in regular arms. Non-widened in the distal part.

BASAL PART. In S. aurantiaca only 2 ventral suckers, in S. pfefferi one transverse row of suckers followed by single sucker in ventral row (in all, 3 suckers: 2 ventral and 1 dorsal). A muscular ridge lateral to the ventral suckers, distal tip directed ventrally, ending in a tooth-like structure that merges with the copulatory apparatus (see next).

COPUlatory apparatus. $3^{\text {rd }}$ and $4^{\text {th }}$ suckerless pedicels of ventral row lengthened, mesially directed, connected at the base to the toothlike structure of the lateral muscular ridge (see above); $2^{\text {nd }}$ and $3^{\text {rd }}$ 
pedicels of dorsal row fused with each other to form an oval structure directed towards the middle of the arm; a few other suckerless pedicels of dorsal row slightly modified.

DistAL PART. Regularly straight and thick. About first 3 suckers of each row markedly enlarged, the remaining ones regularly sized. No widening of arm oral surface between sucker rows.

\section{Additional, non-hectocotylian characters}

Right arm I regular in S. pfefferi, affected by hectocotylization in S. aurantiaca: first two dorsal pedicels suckerless and modified to form a slightly flattened process, directed towards the left dorsal arm. In both species, tentacle club with 8 rows of suckers. Deep funnel indentation and ventral mantle protruding anteriorly on each side of the funnel to form a markedly sinuate margin. Gladius present as a distinct rudiment. Female bursa copulatrix in left ventral part of mantle cavity ear-shaped, comparatively small, not enclosed in a pouch, with noticeable folds converging towards its centre (open type bursa copulatrix).

\section{Remarks}

It is evident that S. aurantiaca and S. pfefferi are sister species, hence they can be placed in an 'aurantiacagroup'. Indeed, differences between the two species are minor: two basal suckers in S. aurantiaca vs three in $S$. pfefferi; right dorsal arm modified in the former vs right dorsal arm regular in the latter. As for the copulatory apparatus, the modified ventral suckers of both species display the distinctive apomorphic feature of being connected to a basal muscular ridge; despite this, they retain the primitive state of lack of connection to the dorsal modified sucker pedicels.

\section{Group H}

Rondeletiola minor and, probably, Inioteuthis capensis.

Description after Naef (1923) and author's personal observations on R. minor.

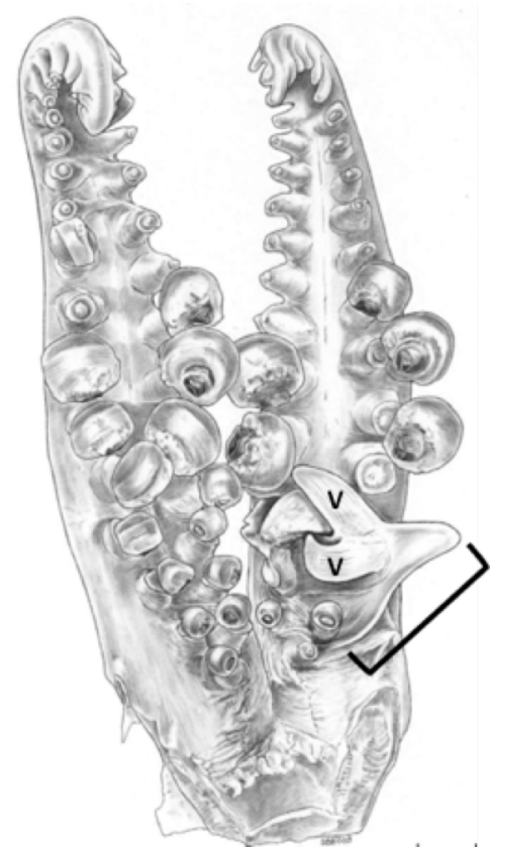

Fig. 15. Pair of dorsal arms of Sepiola pfefferi Grimpe, 1921; the hectocotylus is on the right-hand side. The letters $\mathrm{V}$ indicate the ventral modified pedicels of the copulatory apparatus merging with the muscular ridge (square bracket) arising from the lateral side of basal part (after Goud \& de Heij 2012, modified). 


\section{Hectocotylus}

Overall MORPhOlogy (Fig. 16). Longer and thicker than right arm I, curved aborally, blunt-pointed; suckers in 2 rows as in regular arms; most suckers larger than those in right arm I.

BASAL PART. One transverse row of suckers followed by single sucker in ventral row (in all, 3 suckers: 2 ventral and 1 dorsal).

COPUlatory APPARATUS. Transverse structure formed from two ventral $\left(3^{\text {rd }}\right.$ and $\left.4^{\text {th }}\right)$ and two dorsal $\left(2^{\text {nd }}\right.$ and $3^{\text {rd }}$ ) suckerless pedicels (the $3^{\text {rd }}$ ventral and $2^{\text {nd }}$ dorsal displaced towards the middle of the arm from their longitudinal alignment with the respective sucker rows), modified and fused with each other at their bases; the ventral-most pedicel of the apparatus ( $4^{\text {th }}$ of overall ventral sucker row) is a strongly developed hook-like tooth, directed medially, making an almost complete curve, gradually tapering to a

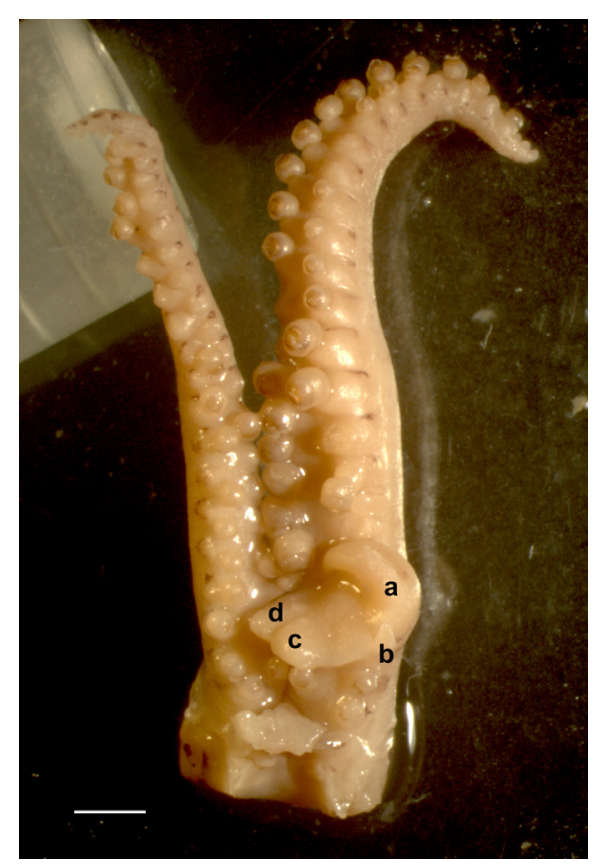

Fig. 16. Pair of dorsal arms of Rondeletiola minor (Naef, 1912) oral view; the hectocotylus is on the right side; $\mathrm{a}, \mathrm{b}, \mathrm{c}, \mathrm{d}$ indicate the $4^{\text {th }}$ ventral, $3^{\text {rd }}$ ventral, $2^{\text {nd }}$ dorsal, $3^{\text {rd }}$ dorsal modified pedicels, respectively, forming the copulatory apparatus. Scale bar: $1 \mathrm{~mm}$.

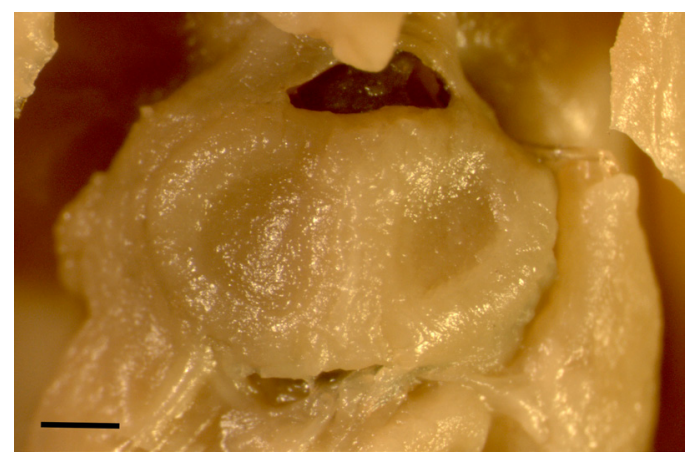

Fig. 17. Visceral light organ of Rondeletiola minor (Naef, 1912) (the hole in the membrane above the light organ was accidental). Scale bar: $0.5 \mathrm{~mm}$. 
point; mesially to this, there is a small tooth ( $3^{\text {rd }}$ ventral pedicel); next to it there is a transverse low crest, derived from the fusion of $2^{\text {nd }}$ and $3^{\text {rd }}$ pedicels of dorsal row, raised slightly in the middle of apparatus $\left(2^{\text {nd }}\right.$ dorsal pedicel), and ending in a sharp angle on the dorsal side.

Distal PART. Suckers in dorsal row enlarged with respect to right arm I, gradually tapering to the arm tip; first two suckers of ventral row (i.e., $5^{\text {th }}$ and $6^{\text {th }}$ of hectocotylus overall ventral row, counting from basal to distal end of arm) completely reduced, making space for the hook-like tooth of the copulatory apparatus, followed by some enlarged suckers, then more distally by regular suckers to the arm tip; oral surface between longitudinal rows of suckers not widened.

\section{Additional, non-hectocotylian characters}

Commissure of the mantle-head ligament one third (or less) of the head width. Arm suckers in two longitudinal rows. The tentacle clubs bear 16 longitudinal rows of suckers. Gladius absent. Unpaired visceral light organ, roughly circular, possibly derived from the fusion of two paired light organs (Fig. 17). Female bursa copulatrix in left ventral part of mantle cavity ear-shaped, not enclosed in a pouch, with noticeable folds converging towards its centre (open type bursa copulatrix).

\section{Remarks}

The hectocotylus of $R$. minor looks very much like that of Sepietta, especially S. oweniana (see below), so that Naef (1912b) at first ascribed his new species minor to the genus Sepietta. Later, Naef (1916) discovered its peculiar light organ and deemed it necessary to create a separate genus to accommodate this species (cf. Bello 2015). Rondeletiola is unique in Sepiolinae because of the concomitance of a visceral roundish light organ and the copulatory apparatus formed by both ventral and dorsal modified sucker pedicels. Young \& Vecchione (2004) moved Inioteuthis capensis to the genus Rondeletiola.

\section{Group I}

Genus Sepietta: S. oweniana, S. obscura and S. neglecta.

Description after Naef (1923), Bello (1995), Vecchione \& Young (2004) and author's personal observations.

\section{Hectocotylus}

Overall MORPHOLOGY (Fig. 18). Dorsal arms of approximately equal size. The hectocotylus apex is pointed; the arm may be slightly curved laterally. Suckers in 2 rows, as in regular arms. Widened in the distal part, tapering to a pointed apex.

BASAL PART. Two transverse rows of regular suckers, either complete, i.e., with 4 suckers in total (S. oweniana and $S$. neglecta) or incomplete, i.e., with 3 suckers, the second dorsal one missing (S. obscura).

Copulatory apparatus. Transverse structure formed from two ventral $\left(3^{\text {rd }}\right.$ and $\left.4^{\text {th }}\right)$ and two dorsal $\left(3^{\text {rd }}\right.$ and $4^{\text {th }}$ in $S$. oweniana and $S$. neglecta, $2^{\text {nd }}$ and $3^{\text {rd }}$ in $S$. obscura) suckerless pedicels, modified and fused with each other at their bases, the inner pedicels displaced from their longitudinal alignment with the respective sucker rows towards the middle of the arm; the ventral-most modified pedicel (from $4^{\text {th }}$ ventral sucker) is the longest and curved, hook-shaped (most prominently in S. oweniana); the next one (from $3^{\text {rd }}$ ventral sucker) is tooth-like; the following pedicel is flask-like; the dorsalmost one is short but comparatively wide in a transverse direction, terminating by the insertion of the first two dorsal suckers of the distal part. 
Distal PART. Oral surface between sucker rows widened, moderately (S. obscura) to greatly (S. oweniana); 1-7 proximal suckers of dorsal row enlarged in specific arrangements; markedly lengthened (often finger-like) sucker pedicels in the ventral row.

\section{Additional, non-hectocotylian characters}

Commissure of the mantle-head ligament one third of the head width or narrower. Arm suckers in 2 longitudinal rows. Tentacle club with 12-32 longitudinal rows of minute suckers. Gladius weakly developed. Visceral light organs absent. Female bursa copulatrix in left ventral part of mantle cavity earshaped, not enclosed in a pouch, with noticeable folds converging towards its centre (open type bursa copulatrix).

\section{Remarks}

The configuration of the hectocotylus is quite uniform throughout the genus. In particular, the hectocotylian features shared by $S$. oweniana and $S$. neglecta reveal their probable close relationship. In addition to interspecific variation, Cuccu et al. (2009) showed morphological variation in the hectocotylus of S. oweniana, i.e., anomalous sucker counts in the basal part of $3.8 \%$ of 607 examined males (see also Bello 2019b).

Some authors, instead of S. obscura, list Sepietta petersi (Steenstrup, 1887) (e.g., Sweeney 2001), which is an invalid species according to Bello (2011), since all the syntypes of the latter nominal species actually belong to $S$. oweniana, which has date priority.

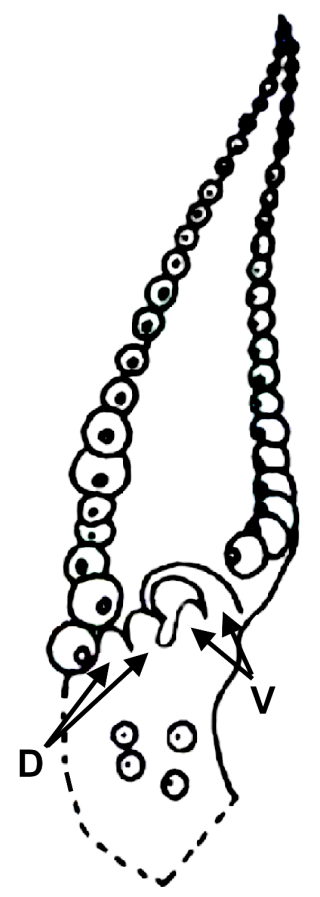

Fig. 18. Hectocotylus of Sepietta oweniana (d'Orbigny, 1841). The arrows starting from the letters V and $\mathrm{D}$ indicate the two ventral and two dorsal modified pedicels, respectively, which form the transversal crest of the copulatory apparatus. 


\section{Group J}

All species in the Sepiola atlantica-group sensu Naef (1923) (cf. Bello 2013; Bello \& Salman 2015): S. affinis, S. atlantica, S. boletzkyi, S. bursadhaesa, S. intermedia, S. robusta, S. rondeletii, S. steenstrupiana and S. tridens de Heij and Goud, 2010.

Description after Naef (1923) and author's personal observations.

\section{Hectocotylus}

Overall MORPHOLOGY (Fig. 19A). Hectocotylus either shorter or equal sized or longer than right dorsal arm; straight or curved laterally (the curvature depends mostly on the distribution of enlarged suckers in the dorsal row of the distal part). Apex blunt. Suckers in 2 rows, as in regular arms. Not, or only slightly widened in the distal part.

BASAL PART. One transverse row of suckers followed by single sucker in ventral row (in all, 3 suckers: 2 ventral and 1 dorsal). In $S$. robusta, the second ventral sucker distinctly enlarged.

Copulatory apparatus. Formed from the $3^{\text {rd }}$ and $4^{\text {th }}$ pedicels of ventral row and $2^{\text {nd }}$ and $3^{\text {rd }}$ pedicels of dorsal row, all of them lengthened and fused with each other lengthwise forming a transverse structure due to the displacement towards the arm midline of the $3^{\text {rd }}$ ventral and $2^{\text {nd }}$ dorsal pedicels; the transverse structure is somewhat coiled toward the oral face of the arm and directed mesially; the $3^{\text {rd }}$ dorsal pedicel

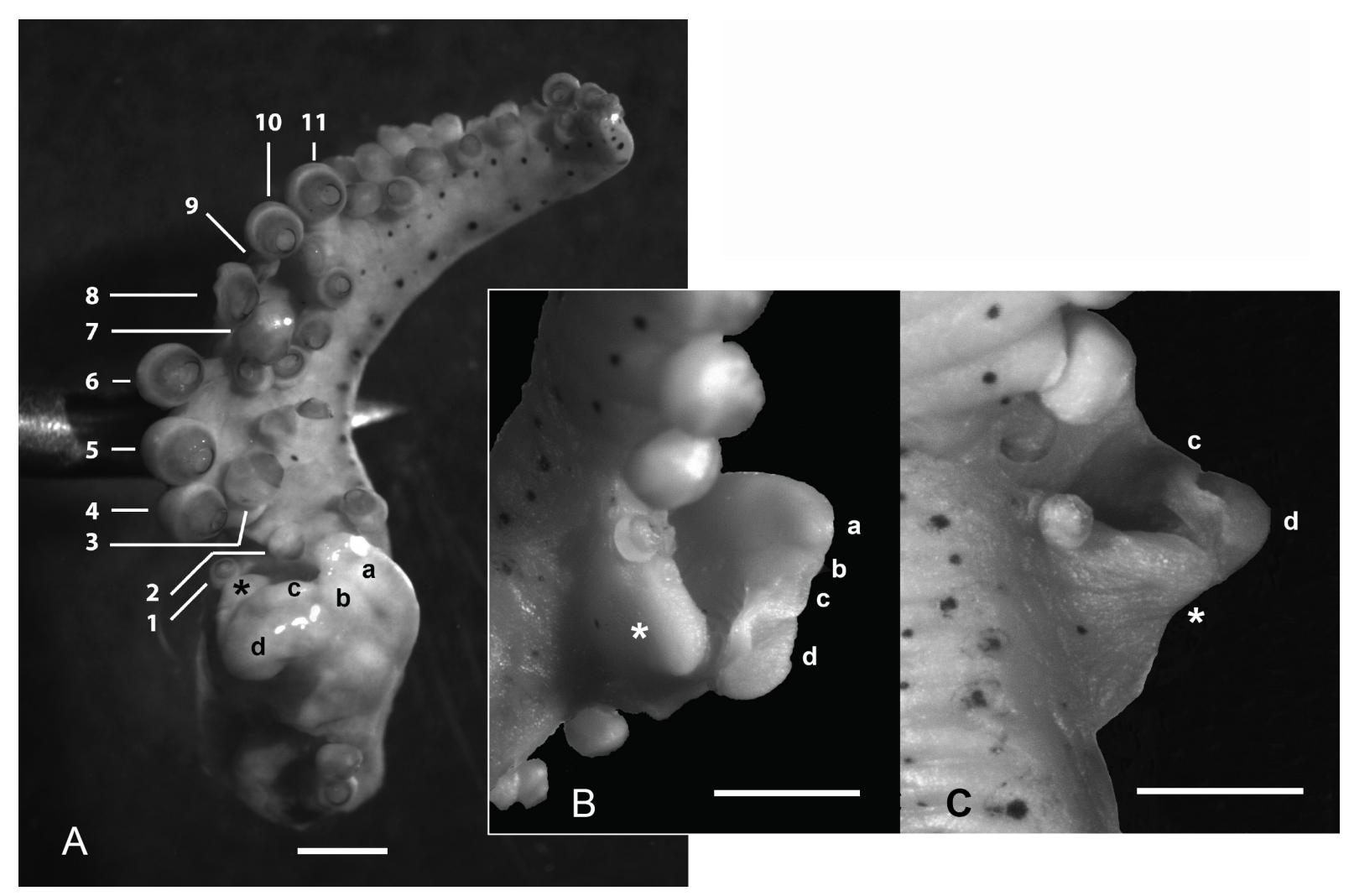

Fig. 19. Hectocotylus of Sepiola boletzkyi Bello \& Salman, 2015; $\mathrm{a}-\mathrm{b}$ and $\mathrm{c}-\mathrm{d}=$ modified ventral and dorsal pedicels, respectively, forming the copulatory apparatus proper; $*=$ lobe in the dorsal sucker row; $1-11=$ heteromorphous suckers in the dorsal row of distal part. A. Hectocotylus, oral-lateral view. B. Copulatory apparatus, mesial view. C. Copulatory apparatus, oblique mesial view. Scale bars: $1 \mathrm{~mm}$ (after Bello \& Salman 2015). 
(named 'tubercle' by Naef 1923) is club-shaped, enlarged at its extremity. Variations: in S. rondeletii the tubercle forms an eyelet; in S. atlantica and S. bursadhaesa the tubercle is wrinkled; in S. steenstrupiana the tubercle is not evident and the copulatory apparatus forms a scroll, distally directed, coiled towards the arm oral surface; in S. boletzkyi the typical four-suckered transverse formation is complemented by a lobe, dorso-mesial of tubercle, formed from suckerless pedicels of dorsal row (Fig. 19B-C).

DISTAL PART. Some suckers in dorsal row enlarged (different arrangement in different species), markedly in S. affinis, S. atlantica, S. boletzkyi, S. bursadhaesa, S. intermedia and S. tridens, moderately in S. robusta and $S$. rondeletii. In $S$. robusta, oral surface of arm widened between the rows of suckers. An evident groove in the meso-lateral side of the arm in S. atlantica, S. affinis, S. intermedia and S. bursadhaesa (Fig. 20); just a hint of groove in S. robusta. Hectocotylus laterally curved in S. atlantica, S. affinis, S. intermedia, S. robusta and S. rondeletii, because of enlargement of dorsal row suckers.

\section{Additional, non-hectocotylian characters}

Commissure of the mantle-head ligament one third of the head width or narrower. Suckers in 2 rows on arms I to III and at least proximally in arm IV; the tip of the latter arms is heteromorphous in S. atlantica, S. steenstrupiana and S. tridens and bears 4 to 8 sucker series. Tentacular clubs with suckers in 8 or fewer longitudinal rows. Ventral mantle margin slightly sinuate, without any deep funnel indentation. Gladius present as a distinct rudiment. Female bursa copulatrix in left ventral part of mantle cavity earshaped, not enclosed in a pouch, with noticeable folds converging towards its centre (open type bursa copulatrix) (Fig. 8B), large, i.e., extending for most of left mantle cavity side, or moderately large; in $S$. rondeletii a small caecum displaces the sagittal mantle septum into the right side of the mantle cavity.

\section{Remarks}

The hectocotylus in the Sepiola atlantica-group is quite uniform among species, which is a firm indication of their close affinity; it differs slightly only in S. steenstrupiana. Other differences concern

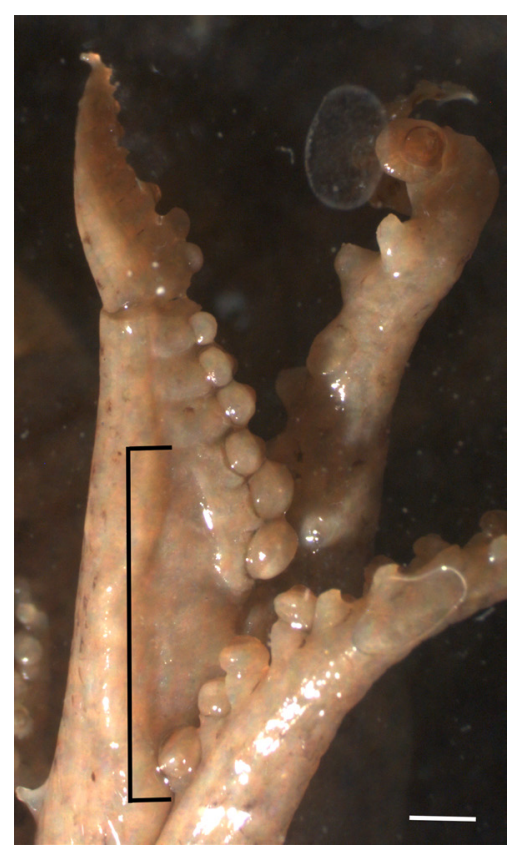

Fig. 20. Hectocotylus of Sepiola bursadhaesa Bello, 2013; mesial view. The square bracket encompasses the groove in the mesial lateral side (the arm in the foreground is the first right one). Scale bar: $2 \mathrm{~mm}$. 
the size of suckers in the dorsal row of the distal part and the occurrence of a groove in the meso-lateral side of arm in some species.

The species $S$. rossiaeformis Pfeffer, 1884 was not included in this group since its status is seemingly unresolved (Vecchione \& Young 2003). In fact, its specific status is not sufficiently justified in its original description, based on only one specimen (since lost), a male $6.1 \mathrm{~mm}$ in mantle length, which might be applicable to Inioteuthis rather than Sepiola; nor it is warranted by subsequent reliable investigations. Hence it is regarded as a nomen dubium and will not be considered here.

The hectocotylian peculiarities of each above described group are reported in Table 1.

\section{Overall remarks on hectocotyli of Sepiolinae}

According to the above descriptions, the hectocotylus displays appreciable differences among diverse species-groups in Sepiolinae, which do not correlate with previously accepted taxonomy. In all, ten different hectocotylian basic patterns (described above) may be distinguished in this subfamily: Euprymna with biseriate arm suckers, Euprymna with tetraseriate arm suckers, Sepiola knudseni, Inioteuthis, the Sepiola birostrata-group, Sepiola ligulata, the Sepiola aurantiaca-group, Rondeletiola, Sepietta and the Sepiola atlantica-group.

The main differences apply to the copulatory apparatus, formed by modified sucker pedicels. In its simplest form - likely the primitive form or plesiomorphic character state, based on basic cladistics principles (e.g., Minelli 1993) - the copulatory apparatus is formed by a single papilla derived from the $3^{\text {rd }}$ pedicel of the ventral sucker row that has lost its sucker and has become elongated to form a blunt, straight, coniform process (papilla) distally directed and tapering (species of Euprymna with biseriate arm suckers). From this, more complex configurations appear to have evolved, involving few or several pedicels, either in the ventral row only or in both the ventral and dorsal rows. These may be slightly or highly modified.

\section{Hypothesized evolution of the modified ventral sucker pedicels}

Two independent evolutionary pathways are evident following a detailed examination of the morphology of the ventral modified pedicels: one relates to the number and the other to the shape of the modified pedicels (Table 1). They range in number from one, which I hypothesize is the plesiomorphic condition (Euprymna with biseriate arm suckers), to two (most other species), three (S. knudseni) or several (Inioteuthis). As stated above, the simplest type of modified pedicel is the form of a papilla. From this, a horn-like modification likely developed (in the $S$. birostrata-group, the $S$. aurantiaca-group, S. ligulata, S. knudseni and Inioteuthis), which further modified to form a longer and very curved hooklike structure (Rondeletiola, Sepietta). In the S. atlantica-group, a rather different structure appears to derive from the fusion lengthwise of the $3^{\text {rd }}$ and $4^{\text {th }}$ pedicels, which likely represents an apomorphic condition. The modified ventral pedicels of Inioteuthis display two autapomorphies: the three horn-like pedicels are joined by a web and, distal to them, some additional pedicels are modified in a unique way (see above Group D).

\section{Hypothesized evolution of the modified dorsal sucker pedicels}

A clear-cut dichotomy separates the species without modified dorsal sucker pedicels (all nominal species of Euprymna and S. knudseni), which I hypothesize is the plesiomorphic character state, from all other species. The latter display copulatory apparati with a variable number of modified dorsal pedicels, which represent apomorphic character states. A further dichotomy partitions the species with the dorsal pedicels separate from the ventral ones (S. ligulata, S. aurantiaca-group, S. birostrata-group) from those with the dorsal pedicels fused with the ventral ones, at their bases only (Rondeletiola and Sepietta) or 
Table 1. Hectocotylus modifications in Sepiolinae; 4- and 2-Euprymna: tetraseriate and biseriate sucker species, respectively; V and D: suckers/pedicels of ventral and dorsal row, respectively.

\begin{tabular}{|c|c|c|c|c|c|c|c|}
\hline & \multirow[t]{3}{*}{ Group } & \multirow{3}{*}{$\begin{array}{c}\text { Basal part: } \\
\text { number of } \\
\text { suckers }\end{array}$} & \multicolumn{4}{|c|}{ Copulatory apparatus } & \multirow[t]{3}{*}{ Distal part } \\
\hline & & & \multicolumn{2}{|c|}{ Ventral row } & \multicolumn{2}{|r|}{ Dorsal row } & \\
\hline & & & $\begin{array}{l}\text { modified } \\
\text { pedicels }\end{array}$ & $\begin{array}{c}\text { type of } \\
\text { modification }\end{array}$ & $\begin{array}{l}\text { modified } \\
\text { pedicels }\end{array}$ & $\begin{array}{c}\text { type of } \\
\text { modification }\end{array}$ & \\
\hline A & 2-Euprymna & $\begin{array}{l}2 \text { complete } \\
\text { rows }\end{array}$ & $1\left(3^{\mathrm{rd}}\right)$ & papilla & none & none & $\begin{array}{l}\text { palisade, suckers } \\
\text { without fleshy } \\
\text { caps }\end{array}$ \\
\hline B & 4-Euprymna & $\begin{array}{l}2 \text { complete } \\
\text { rows }\end{array}$ & $\begin{array}{l}1\left(3^{\text {rd }}\right) \text { or } 2 \\
\left(3^{\left.\text {rd }-4^{\text {th }}\right) \text { or }}\right. \\
3\left(3^{\text {rd }}-5^{\text {th }}\right)\end{array}$ & papillae & none & none & $\begin{array}{l}\text { palisade, suckers } \\
\text { with fleshy caps }\end{array}$ \\
\hline $\mathrm{C}$ & S. knudseni & $\begin{array}{l}1 \text { ventral } \\
\text { sucker }\end{array}$ & $3\left(2^{\text {nd }}-4^{\text {th }}\right)$ & $\begin{array}{l}\text { horns, bluntly } \\
\text { pointed, } \\
\text { fused }\end{array}$ & none & none & $\begin{array}{l}4 \text { middle D } \\
\text { enlarged, several } \\
\text { V suckers missing }\end{array}$ \\
\hline $\mathrm{D}$ & Inioteuthis & $2 \mathrm{~V}+1 \mathrm{D}$ & $\begin{array}{l}3 \text { proximal } \\
\left(3^{\text {rd }}-5^{\text {th }}\right)+ \\
4 \text { distal }\end{array}$ & $\begin{array}{l}\text { horns joined } \\
\text { by web }+ \\
\text { laminae, fused }\end{array}$ & $\begin{array}{l}6 \\
\left(2^{\text {nd }}-7^{\text {th }}\right)\end{array}$ & $\begin{array}{l}\text { horns, all joined by } \\
\text { web, joined also } \\
\text { with ventral horns }\end{array}$ & first $V$ enlarged \\
\hline $\mathrm{E}$ & $\begin{array}{l}\text { S. birostrata- } \\
\text { group }\end{array}$ & $\begin{array}{l}2 \text { complete } \\
\text { rows }\end{array}$ & $2\left(3^{\text {rd }-4^{\text {th }}}\right)$ & $\begin{array}{l}\text { horns, } 3^{\text {rd }} \\
\text { smaller }\end{array}$ & $2\left(3^{\text {rd }}-4^{\text {th }}\right)$ & laminae & leafy pedicels \\
\hline $\mathrm{F}$ & S. ligulata & $2 \mathrm{~V}+1 \mathrm{D}$ & $\begin{array}{l}2 \\
\left(3^{\text {rd }}-4^{\text {th }}\right)\end{array}$ & $\begin{array}{l}\text { horn }+ \\
\text { tubercle }\end{array}$ & $\begin{array}{l}2\left(2^{\text {nd }-~}-3^{\text {rd }}\right) \\
+2-3 \\
+2\end{array}$ & $\begin{array}{l}\text { elongated, fused } \\
\text { ('spatula') }+ \\
\text { elongated laminate, } \\
\text { fused ('ligula') + } \\
\text { tubercles }\end{array}$ & $\begin{array}{l}\text { all V enlarged, } \\
\text { pedicels } \\
\text { lengthened, arm } \\
\text { surface widened }\end{array}$ \\
\hline G & $\begin{array}{l}\text { S. aurantiaca- } \\
\text { group }\end{array}$ & $\begin{array}{l}2 \mathrm{~V}+\text { none } \\
\text { or } 1 \mathrm{D}+ \\
\text { ventral } \\
\text { ridge }\end{array}$ & $2\left(3^{\text {rd }-4^{\text {th }}}\right)$ & $\begin{array}{l}\text { horns, bases } \\
\text { connected } \\
\text { with basal } \\
\text { ventral ridge }\end{array}$ & $\begin{array}{l}2\left(2^{\text {nd }}-3^{\text {rd }}\right) \\
+ \text { few } \\
\text { more }\end{array}$ & $\begin{array}{l}\text { fused into oval } \\
\text { structure }+ \\
\text { tubercles }\end{array}$ & $\begin{array}{l}\text { first } 3 \mathrm{D} \text { and } \mathrm{V} \\
\text { enlarged }\end{array}$ \\
\hline $\mathrm{H}$ & Rondeletiola & $2 \mathrm{~V}+1 \mathrm{D}$ & $2\left(3^{\text {rd }}-4^{\text {th }}\right)$ & tooth + hook & $2\left(3^{\text {rd }}-4^{\text {th }}\right)$ & $\begin{array}{l}\text { tubercles, fused } \\
\text { with ventral } \\
\text { pedicels to form a } \\
\text { transverse low crest }\end{array}$ & all D enlarged \\
\hline I & Sepietta & $\begin{array}{l}2 \mathrm{~V}+2 \mathrm{D} \text { or } \\
2 \mathrm{~V}+1 \mathrm{D}\end{array}$ & $2\left(3^{\text {rd }}-4^{\text {th }}\right)$ & tooth + hook & $\begin{array}{l}2\left(3^{\text {rd }}-4^{\text {th }}\right) \\
\text { or } \\
\left(2^{\text {nd }}-3^{\text {rd }}\right)\end{array}$ & $\begin{array}{l}\text { tubercles, fused } \\
\text { with ventral } \\
\text { pedicels to form a } \\
\text { transverse low crest }\end{array}$ & $\begin{array}{l}\text { a few proximal } \\
\text { D enlarged, arm } \\
\text { surface widened }\end{array}$ \\
\hline $\mathrm{J}$ & $\begin{array}{l}\text { S. atlantica- } \\
\text { group }\end{array}$ & $2 \mathrm{~V}+1 \mathrm{D}$ & $2\left(3^{\text {rd }}-4^{\text {th }}\right)$ & $\begin{array}{l}\text { elongated, } \\
\text { fused with } \\
\text { dorsal pedicels } \\
\text { to form a } \\
\text { transverse } \\
\text { high crest }\end{array}$ & $\begin{array}{l}2\left(2^{\text {nd }-}-3^{\text {rd }}\right) \\
(+1 \text { or } \\
\text { more } \\
\text { tubercles } \\
\text { in few } \\
\text { species })\end{array}$ & $\begin{array}{l}\text { elongated, fused } \\
\text { with ventral } \\
\text { pedicels to form } \\
\text { a transverse high } \\
\text { crest }\end{array}$ & $\begin{array}{l}\text { a few D enlarged; } \\
\text { some species } \\
\text { with pedicels } \\
\text { lengthened and/or } \\
\text { groove in mesial } \\
\text { lateral side }\end{array}$ \\
\hline
\end{tabular}

throughout their length (S. atlantica-group), to give rise to a transverse structure (crest) either low or high, respectively. The fusion of dorsal with ventral modified pedicels is a synapomorphic state for the assemblage Rondeletiola + Sepietta + S. atlantica-group; the character trait of elongated pedicels fused throughout their length is an autapomorphy of the $S$. atlantica-group. A different synapomorphy joins the $S$. aurantiaca-group to $S$. ligulata: that is, the fusion of the $2^{\text {nd }}$ and $3^{\text {rd }}$ dorsal pedicels into a structure 
positioned in the middle of the arm oral face, to which further pedicels, mesially directed, are added. Once again, Inioteuthis is an outstanding case because several more sucker pedicels from both rows contribute to the formation of its copulatory apparatus; moreover, all dorsal pedicels and the ventroproximal ones are joined by a web to form a helix-like structure. This hectocotylus is the most complex among Sepiolinae and denotes a unique autapomorphic condition that makes its derivation difficult to trace from a possible ancestral state. However, its ventro-proximal horn-like pedicels suggest a possible affinity with the $S$. birostrata-group.

\section{Distal part}

The morphology of the distal part of the hectocotylus also aids to differentiate groups of species. A peculiar condition, strikingly dissimilar from that of the other genera, is found in all nominal Euprymna species: the palisaded sucker/pedicel complex. Two types of palisades may be recognized in this group: suckers with or without a conspicuous fleshy cap in species with tetra- or biseriate arm suckers, respectively. Sepiola birostrata too displays peculiar, i.e., leaf-like, sucker pedicels in the hectocotylus distal part; in addition, the dorsal pedicels of the same type constitute the pad in the copulatory apparatus. In the other groups of species, modifications of the distal part consist of the enlargement of distinctive sets of suckers, lengthening of pedicels, widening of the arm oral surface and presence of a groove in its meso-lateral face. All of these modifications may be diagnostic at the species level.

\section{Basal part and hectocotylus relative length}

In contrast, the basal part is the most conservative and uniform portion of the hectocotylus throughout the genera. Only in S. robusta, S. knudseni and the S. aurantiaca-group does the size or the number of the basal suckers have a diagnostic significance.

Lastly, the relative length of the left dorsal arm with respect to the right one appears to be an erratic, or variable character, devoid of any diagnostic value at the generic level.

\section{Final remarks}

As hinted above, fragments of apparent evolutionary trajectories are evident in the hectocotylus of Sepiolinae. Despite the wide morphological diversity in this arm, two traits are common to all sepioline genera and species, namely the hectocotylization of left arm I and the modification of the $3^{\text {rd }}$ sucker pedicel of its ventral row. The former is a trait shared with other taxa, either closely (e.g., the rossiine Semirossia) or non-closely related (e.g., several species of Sepia) (cf. Reid et al. 2005), whereas the latter is unique to Sepiolinae. Hence, this is a autapomorphic feature of Sepiolinae that can be traced in all hectocotyli in this taxon.

In summary, as in most evolutionary modifications, it is not possible via our human interpretation, to determine a single evolutionary trajectory for the copulatory apparatus from the simplest 'one ventral papilla' state to the rather complex structures of I. japonica and S. ligulata. In extant Sepiolinae, we can only observe the end results of a normal reticulate pattern of evolution, rather than the results of an outdated linear evolutionary model. The only clear-cut evolutionary trajectory appears to be that encompassing the Atlantic-Mediterranean Sepiolinae (except S. knudseni), whose ensemble appears to be a well-defined independent major clade, which is also supported by non-hectocotylian character states (see below).

\section{Overall remarks on additional characters of Sepiolinae}

In addition to the hectocotylus, essential diagnostic characters in Sepiolinae systematics include: 1) the exclusive female bursa copulatrix, hence an autapomorphic feature for this taxon; 2) the number of longitudinal sucker rows on the arms; 3 ) the presence and shape of the visceral light organs embedded 
Table 2. Additional diagnostic characters in Sepiolinae.

\begin{tabular}{lccccc}
\hline & $\begin{array}{c}\text { Bursa } \\
\text { copulatrix }\end{array}$ & $\begin{array}{c}\text { Sucker rows } \\
\text { on arms }\end{array}$ & Gladius & Light organ & $\begin{array}{c}\text { Ventral mantle } \\
\text { margin }\end{array}$ \\
\hline 2-Euprymna & closed & 2 & absent & kidney-shaped & slightly sinuate \\
4-Euprymna & closed & $4(-8)$ & absent & kidney-shaped & slightly sinuate \\
S. knudseni & closed & 2 & absent & cordiform & slightly sinuate \\
S. birostrata-group & closed & 2 & absent & kidney-shaped & slightly sinuate \\
S. ligulata & open & 2 & reduced & kidney-shaped & indented \\
S. aurantiaca-group & open & 2 & reduced & kidney-shaped & indented \\
Inioteuthis & closed & 2 & absent & absent & slightly sinuate \\
Rondeletiola & open & 2 & absent & oval, bipartite & slightly sinuate \\
Sepietta & open & 2 & reduced & absent & slightly sinuate \\
S. atlantica-group & open & 2 & reduced & kidney-shaped & slightly sinuate \\
\hline
\end{tabular}

in the ink sac; 4) the presence/absence of the gladius (that is reduced when present) and finally, 5) the ventral mantle margin, that may be straight/slightly sinuate or indented (Table 2).

1. Bursa copulatrix: the 'enclosed-in-a-pouch' or closed type (all nominal species of Euprymna, S. birostrata, S. knudseni, Inioteuthis) appears to be a plesiomorphic character state with respect to the 'ear-shaped-not-enclosed' or open type (Rondeletiola, Sepietta, S. ligulata, S. aurantiaca-group and S. atlantica-group). In fact, vestiges of the pouch cover and its connections to the inner mantle surface are visible in $S$. boletzkyi, S. bursadhaesa, S. rondeletii and possibly S. affinis, indicating that the bursa copulatrix 'open type' is most probably an apomorphic state with respect to the covered type.

2. Number of longitudinal sucker rows on the arms: the biseriate condition (most sepioline species) is seemingly the plesiomorphic character state of the tetraseriate condition (all nominal species of Euprymna except E. pardalota, E. parva and E. phenax).

3. Visceral light organs: there are four structural patterns: paired kidney-shaped organs (all nominal Euprymna and all nominal species of Sepiola, except S. knudseni); paired oval organs joining along the sagittal plane (Rondeletiola); unpaired cordiform organ (S. knudseni), and completely reduced organs (Sepietta and Inioteuthis). The paired kidney-shaped light organs represent the plesiomorphic state. The light organ in Rondeletiola is seemingly less derived, i.e., basically similar to that of Semirossia (cf. Boletzky 1970) and corresponds to late embryonic phases of visceral light organ development (Foster et al. 2002). Also, the cordiform light organ of S. knudseni might possibly represent a similar situation of suspended development in its initial phase. Lastly, the complete reduction of light organs is deemed an apomorphic state that may have derived from any previous light organ state; such a reduction may have occurred more than once (Nishiguchi et al. 2004) and, therefore, there is no ground to consider it a synapomorphic feature of the genera Sepietta and Inioteuthis.

4. Gladius: its complete reduction (all nominal species of Euprymna, Inioteuthis, Rondeletiola, the S. birostrata-group and, possibly, S. knudseni) appears to be a derived state with respect to its partial reduction (Sepietta, S. ligulata, the S. aurantiaca-group, and the S. atlantica-group). The reduction, either partial or total, of this organ may be related to the reduction in the size of Sepiolinae with respect to their ancestors. 
5. Ventral mantle margin: although a trait of minor importance, its deep indentation is a feature of the S. aurantiaca-group and S. ligulata.

It is noteworthy that the character states, 'open bursa copulatrix' and 'reduced gladius', always co-occur except for Rondeletiola (Table 2).

\section{Polyphyly of Sepiola and Euprymna}

The above considerations of both hectocotylian and non-hectocotylian characters indicate that the nominal genus Sepiola - the most numerous generic taxon - is clearly not homogeneous. The diversity of hectocotylus morphologies is further supported by other anatomical characters, namely the shape of the bursa copulatrix, the luminous glands and, to a lesser degree, the ventral mantle border. In cladistic terms, Sepiola as previously understood is a polyphyletic taxon.

The Sepiola knudseni hectocotylus differs because only the sucker-pedicel elements of the ventral row are modified to form the copulatory apparatus, contrary to all other nominal species in Sepiola. The unicity of knudseni is also powerfully corroborated by its unique cordiform visceral light organ. These characters are substantial enough to warrant the erection of a new genus to accommodate this species.

The hectocotylus of S. birostrata diverges from all other types by the leafy pedicels in the distal part, which is a distinctive autapomorphic feature. An additional hectocotylian distinctive feature, also shared by $S$. trirostrata, is the unique coalescence of flattened dorsal pedicels into a pad, medial to the ventral horns. In addition, there is seemingly a close morphological affinity between these flattened pedicels, the following dorsal low transversal ridges and the leafy pedicels in the distal part of the hectocotylus of S. birostrata. Lastly, the dorsal keel of the hectocotylus found in some specimens of this species occurs in no other nominal species of Sepiola. In addition, the female bursa copulatrix is enclosed in a pouch (closed type bursa copulatrix), a condition very different from the ear-shaped open type bursa copulatrix of both the north-eastern Atlantic-Mediterranean nominal species of Sepiola (except S. knudseni) and the genera Rondeletiola and Sepietta.

As for the atlantica-group, its uniform copulatory apparatus, mainly formed from two ventral and two dorsal modified suckerless pedicels lengthened and fused with each other throughout their length is, in fact, an autapomorphic character state that clearly distinguishes this clade from all other species.

Both Sepiola ligulata and the aurantiaca-group, despite their hectocotylian dissimilarities, share plesiomorphic and apomorphic features that support their placement in a clade on their own. The main symplesiomorphic character concerns the copulatory apparatus, in particular the $3^{\text {rd }}$ and $4^{\text {th }}$ ventral sucker pedicels modified into horns that are separate from the dorsal modified pedicels; the connection of the ventral horns to the basal muscular ridge is an autapomorphic character state of the aurantiacagroup. Synapomorphic character states shared by these three species are represented by the modification of several suckerless pedicels from the dorsal row: the $2^{\text {nd }}$ and $3^{\text {rd }}$ pedicels may be fused with each other into a structure projecting slightly (in the aurantiaca-group) or very extensively (the spatula of S. ligulata) into the middle of the hectocotylus; a few pedicels, next in mesial direction, may be fused with each other into a small (aurantiaca-group) or large prominent structure (the ligula of S. ligulata). An additional synapomorphic feature is the ventral mantle protruding anteriorly on each side of the funnel to form a markedly sinuate margin.

In summary, the above described situation provides clear evidence that the genus Sepiola as previously understood is not monophyletic and, as such, is no longer tenable in that configuration. The S. atlanticagroup, the S. aurantiaca-group + S. ligulata, the S. birostrata-group and S. knudseni should clearly be treated as distinct genera. 
As for the nominal species of Euprymna - the second most speciose genus - it is also evident that it includes two separate, though closely-related, clades: one with tetraseriate sucker arms and fleshy caps on palisaded suckers; the other with biseriate sucker arms and devoid of fleshy caps.

\section{Phylogenetic relationships within Sepiolinae}

Taking into consideration the features examined here, it is possible to hypothesize a cladogram for Sepiolinae (Fig. 21). The apomorphic features of each clade, numbered in the cladogram, are explained here below.

1. The synapomorphic character states that distinguish Sepiolinae from Rossiinae are: male left dorsal arm hectocotylized with third ventral sucker pedicel elongated, coniform (primordial state of copulatory apparatus); presence of a pouch-like bursa copulatrix (closed type) in left ventral side of female mantle cavity; dorsal mantle margin fused to head by cutaneous occipital band; arms with two longitudinal rows of suckers; gladius rudimentary; visceral light organs kidney-shaped, embedded in ink sac; small-sized body. (Some of these features also occur in some genera of Rossiinae, but not all together.)

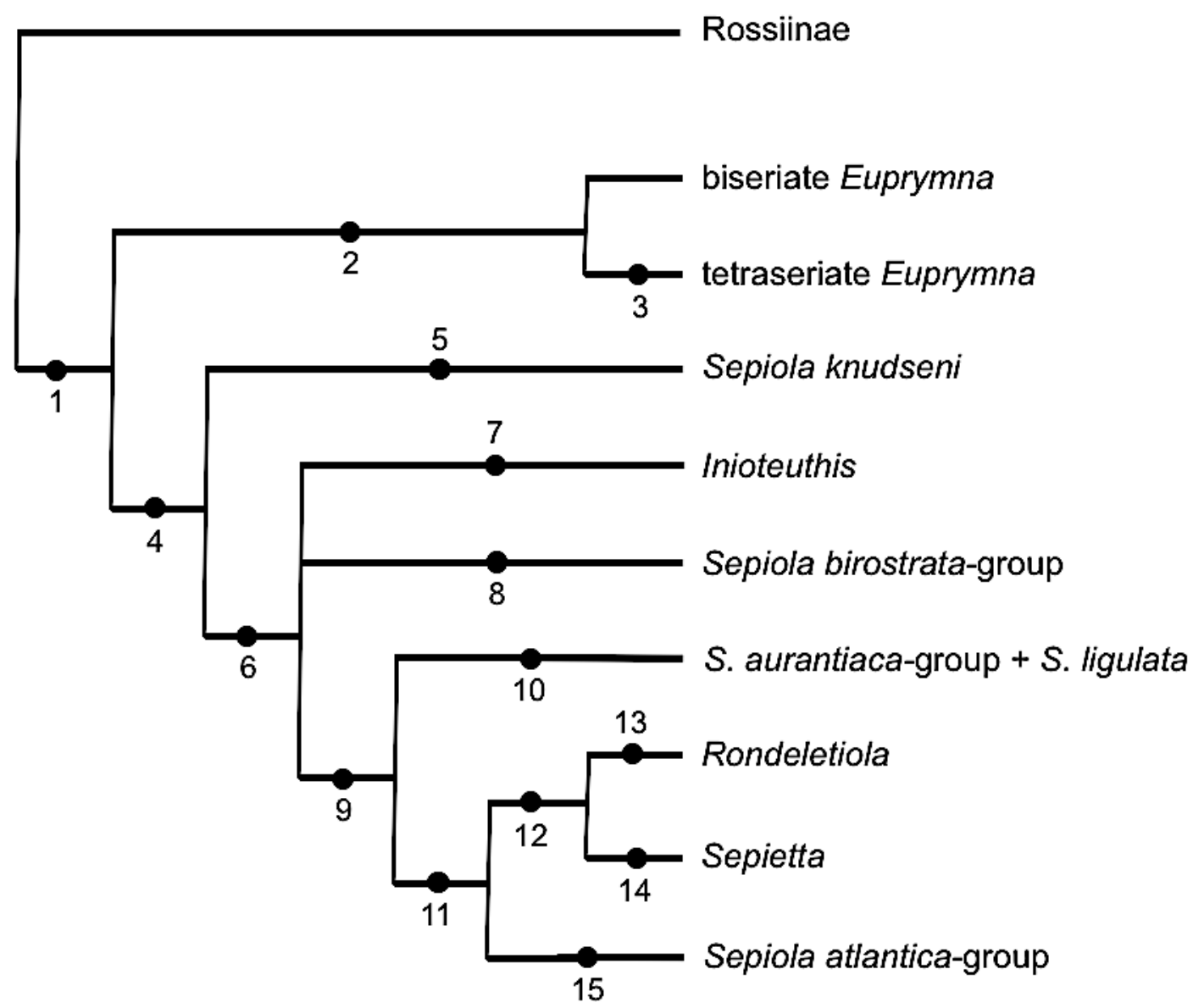

Fig. 21. Cladogram of Sepiolinae Leach, 1817. See text for explanation of numbered apomorphic features. 
2. The main apomorphy of the clade grouping all nominal species in Euprymna is the palisaded columnar suckers in the distalmost portion of the hectocotylus. This group occupies a basal position because of the copulatory apparatus primitive state. This clade can be divided into two sub-clades, one comprising the tetraseriate sucker species and the other the biseriate sucker ones.

3. Four, exceptionally eight, rows of suckers on all arms. The columnar pedicels of the ventral row are joined by a membrane; there is a well-developed fleshy cap on the palisade suckers.

4. The sister clade to the Euprymna-group, which includes all the remaining members of Sepiolinae, is mainly characterized by the further development of the hectocotylus copulatory apparatus; the modified pedicels are not papilla-like.

5. In Sepiola knudseni, the copulatory apparatus is formed by three horn-like pedicels from the ventral row; in addition, several ventral sucker/pedicel elements in the hectocotylus distal part are completely reduced; lastly, the visceral light organ is cordiform.

6. The synapomorphic character state of the clade comprising all the other species is the participation of pedicels from both the ventral and the dorsal rows (two from each row) in the formation of the copulatory apparatus. Three sub-clades can be recognized in this clade: the genus Inioteuthis, the Sepiola birostratagroup, and the ensemble of NE Atlantic-Mediterranean taxa (namely Rondeletiola, Sepietta, the Sepiola atlantica-group, the Sepiola aurantiaca-group and Sepiola ligulata). The relationships among these three sub-clades are not fully explained because of the marked differences of the Inioteuthis peculiar hectocotylus (i.e., a more advanced state) from the other two sub-clades.

7. The autapomorphies that single out Inioteuthis are the copulatory apparatus with the highest number of modified pedicels in the ventral sucker row (seven instead of two or three) and several slightly modified, web-joined pedicels in the dorsal sucker row (six), and the complete reduction of the visceral light organs.

8. The autapomorphic modification that identifies the Sepiola birostrata-group is the leaf-like pedicels in the hectocotylus distal part. The modified dorsal pedicels of the copulatory apparatus are also leafy and are fused to the arm oral side to form a pad.

9. The main feature distinguishing the NE Atlantic-Mediterranean clade is the open type bursa copulatrix, that is a synapomorphic character state with respect to the pouch-like bursa copulatrix observed in all other groups, including S. kundseni. This character and the copulatory apparatus basically formed by two ventral and two dorsal modified pedicels (the latter character occurring also in the birostrata-group) render this clade a well-defined one.

10. In addition to the character "ventral pedicels separate from the dorsal ones in the copulatory apparatus', which is a plesiomorphic character state, the clade encompassing the Sepiola aurantiacagroup + Sepiola ligulata is defined by the apomorphic states ' $2^{\text {nd }}$ and $3^{\text {rd }}$ dorsal pedicels fused into a structure projecting to the middle of arm distal part + additional modified dorsal pedicels' and 'mantle ventral margin deeply indented'; in particular, these are the only species in Sepiolinae to display the latter character state.

11. The sister clade of the one above, i.e., (Sepiola atlantica-group (Rondeletiola, Sepietta)), is characterized by the copulatory apparatus deriving from the fusion with each other of two ventral and two dorsal pedicels to make a transverse formation. 
12. The copulatory apparatus pedicels are short in Rondeletiola and Sepietta except the ventral-most one, which curves hook-like. These genera are distinguished from each other by two different apomorphic states of the character 'visceral light organs'.

13. In Rondeletiola the visceral light organs are fused into a round sagittal organ.

14. In Sepietta the visceral light organs are completely reduced.

15. In the Sepiola atlantica-group the four modified pedicels of the copulatory apparatus are lengthened and fused with each other throughout their length.

According to the above cladogram, the current, traditional subdivision of Sepiolinae species into Sepiola, Euprymna, Inioteuthis, Rondeletiola and Sepietta is no longer tenable. In fact, the polyphyletic condition of the genus Sepiola makes it necessary to erect three new genera to accommodate 1) the birostrata-group; 2) the aurantiaca-group + ligulata, and 3) the species knudseni. The genus Euprymna as well, as presently understood, is clearly composed of two distinguishable clades, which are best dealt with as separate genera.

\title{
Diagnoses of the genera in Sepiolinae
}

The diagnoses of the new genera and the revised diagnoses of the established genera in Sepiolinae are provided below. The genera are listed alphabetically following the nominal genus.

\author{
Class Cephalopoda Cuvier, 1797 \\ Subclass Coleoidea Bather, 1888 \\ Order Sepiolida Fioroni, 1981 \\ Family Sepiolidae Leach, 1817
}

Subfamily Sepiolinae Leach, 1817

Sepiolinae Leach, 1817: 137; nom. transl. ex Appellöf, 1898. Type genus: Sepiola Leach, 1817.

\section{Diagnosis}

Mantle broad, U-shaped, dorsally fused with head in nuchal region by occipital band; without ventral mantle shield. Fins rounded or slightly pointed; their length to about half mantle length or slightly greater, posteriorly not reaching the mantle rear end. Interbrachial web weakly developed between arms I-III. Arm suckers in 2 or 4, exceptionally 8, longitudinal rows. Left dorsal arm of male hectocotylized. Bursa copulatrix present near female genital opening in the left ventral side of mantle cavity. Visceral photophores present or absent. Gladius reduced or absent. (Modified after Vecchione \& Young 2004 and Reid \& Jereb 2005).

Sepiola Leach, 1817

Figs 8B, 19-20

Sepiola Leach, 1817: 137.

\section{Type species}

Sepiola rondeletii Leach, 1817, by monotypy. 


\section{Diagnosis}

Sepiolinae with fins rounded; their length about half mantle length. Suckers biseriate on arms I to III and at least proximally on arm IV. Tentacle club suckers in 4 to 8 longitudinal rows. Mantle-head occipital band narrow (not reaching over the ocular globes). A pair of kidney-shaped photophores on ventral surface of ink-sac. Gladius present, reduced. Ventral mantle margin slightly sinuate, without any deep funnel indentation. Hectocotylus (male left arm I) tripartite: basal part with three suckers, two ventral and one dorsal; copulatory apparatus with transverse formation of two ventral and two dorsal modified suckerless pedicels, all four of them lengthened and fused with each other throughout their length (few additional dorsal modified pedicels may be present mesially to transverse formation); distal part with some enlarged suckers in dorsal row. Female bursa copulatrix roughly ear-shaped, devoid of cover.

\section{Included species}

Sepiola rondeletii Leach, 1817, S. affinis Naef, 1912, S. atlantica d'Orbigny, 1842, S. boletzkyi Bello \& Salman, 2015, S. bursadhaesa Bello, 2013, S. intermedia Naef, 1912, S. robusta Naef, 1912, S. steenstrupiana Levy, 1912 and S. tridens de Heij \& Goud, 2010.

\section{Remarks}

The revised diagnosis of the genus Sepiola reported above was formulated to comply with the rearrangement of Sepiolinae according to the present results. It dismisses several species previously included in Sepiola, namely S. aurantiaca, S. birostrata, S. knudseni, S. ligulata, S. pfefferi and S. trirostrata, which are better placed in different genera. The revised genus Sepiola includes all the species in the Sepiola atlantica-group sensu Naef 1923 (see also Bello 2013; Bello \& Salman 2015). Hence, the atlantica-group coincides with the genus Sepiola as revised in this paper.

The overall distribution of these species ranges from the north-eastern Atlantic Ocean to the Mediterranean Sea.

Adinaefiola gen. nov.

urn:1sid:zoobank.org:act:D156F532-3035-4FF0-AA5D-3FF6F39D5531

Figs $14-15$ (the generic name used in the captions is the former one)

\section{Type species}

Sepiola ligulata Naef, 1912, here designated.

\section{Diagnosis}

Sepiolinae with fins rounded; their length about half mantle length. Suckers biseriate on all arms. Tentacle club suckers in 8 longitudinal rows. Mantle-head occipital band narrow (not reaching over the ocular globes). A pair of kidney-shaped photophores on ventral surface of ink sac. Gladius present, reduced. Ventral mantle margin with deep funnel indentation and markedly sinuate margin. Hectocotylus (male left arm I) tripartite: basal part either with three suckers, two ventral and one dorsal, or two ventral suckers only; copulatory apparatus with modified suckerless pedicels: two ventral pedicels horn- or tubercle-like, two dorsal pedicels separate from ventral ones, fused with each other and distally directed between the two rows of suckers of distal part, additional dorsal pedicels projecting toward right arm I; distal part with some enlarged suckers in either ventral or both rows. Female bursa copulatrix roughly ear-shaped, devoid of cover. 


\section{Included species}

Adinaefiola ligulata (Naef, 1912) gen. et comb. nov., A. aurantiaca (Jatta, 1896) gen. et comb. nov. and A. pfefferi (Grimpe, 1921) gen. et comb. nov.

\section{Etymology}

This generic name is created to honour the memory of Adolf Naef (1883-1949), founder of modern teuthology and a major scholar of Sepiolinae; it derives from the combination of Adi, the name that the scientist was called by his family members, with surname, Naef, and the diminutive suffix -iola. Gender feminine.

\section{Discussion of affinities}

Adinaefiola gen. nov. fits in the clade of NE Atlantic-Mediterranean Sepiolinae, characterized by the open-type bursa copulatrix and the extant, though reduced, gladius. Its affinities with Sepiola, as understood here, are mainly limited to the same type of light organs, kidney-shaped, and the same type of bursa copulatrix, character state shared by all NE Atlantic-Mediterranean Sepiolinae (Rondeletiola, Sepietta and Sepiola). It differs from Sepiola (the genus in which its species were previously placed) in that the modified sucker pedicels in the dorsal row of the copulatory apparatus are separate from the ventral ones. Moreover, the ventral mantle margin is indented and enlarged suckers are also present in the ventral row of the hectocotylus distal part, whereas neither of these two character states occurs in Sepiola s.s.

\section{Remarks}

Adinaefiola gen. nov. is established to accommodate the species ligulata, aurantiaca and pfefferi, which should be removed from Sepiola because of their sound differences from the true members of that genus (see above). Adinaefiola aurantiaca gen. et comb. nov. and A. pfefferi gen. et comb. nov. are clearly sister species - the former Mediterranean and the latter from the NE Atlantic (Goud \& de Heij 2012) both of which ostensibly differ from $A$. ligulata gen. et comb. nov. Nevertheless, the three species in this new genus, in addition to the symplesiomorphic character state 'dorsal pedicels of copulatory apparatus separate from ventral pedicels', share a few synapomorphies: the $2^{\text {nd }}$ and $3^{\text {rd }}$ modified dorsal pedicels of the hectocotylus are fused with each other and protruding in the middle of the arm; additional modified dorsal pedicels in the copulatory apparatus are separate from the first two, and are mesially directed; and the ventral mantle margin has a deep funnel indentation. In turn, A. aurantiaca and A. pfefferi have a unique muscular ridge projecting laterally from the hectocotylus basal part, which ends in a toothlike structure merging with the ventral pedicels of the copulatory apparatus; this is a synapomorphic character state of the two species.

Boletzkyola gen. nov.

urn:1sid:zoobank.org:act:AA294852-E5A5-40E6-A8F4-288A22290823

Figs 10-11 (the generic name used in the captions is the former one)

\section{Type species}

Sepiola knudseni Adam, 1984, here designated.

\section{Diagnosis}

Sepiolinae with fins rounded; their length about half mantle length. Suckers biseriate on all arms. Tentacle club suckers in 8 longitudinal rows. Mantle-head occipital band narrow (not reaching over the ocular globes). A single cordiform photophore on ventral surface of ink sac. Ventral mantle margin slightly sinuate, without any deep funnel indentation. Hectocotylus (male left arm I) tripartite: basal part with 
one incomplete transverse row of suckers (only the ventral one is present); copulatory apparatus with three ventral modified suckerless pedicels enlarged and lengthened into thick, bluntly pointed horn-like structures; distal part with several suckers missing proximally in ventral row and four enlarged suckers in dorsal row. Female bursa copulatrix pouch-like with wide opening.

\section{Included species}

Boletzkyola knudseni (Adam, 1984) gen. et comb. nov.

\section{Etymology}

This genus is named in honour of Sigurd von Boletzky (formerly Observatoire Arago / CNRS, Banyulssur-Mer, France; presently retired) for his outstanding contribution to the study of cephalopods, including Sepiolinae, and to the enhancement of Mediterranean teuthology; it is formed by his family name and the diminutive suffix -ola. Gender feminine.

\section{Discussion of affinities}

Boletzkyola gen. nov. differs from all other genera and species-groups in Sepiolinae because of its unique cordiform visceral light organ (different from that of Rondeletiola; see below). It differs from all genera with a copulatory apparatus involving dorsal modified pedicels. As for the other species sharing the character state 'only ventral modified pedicels in the copulatory apparatus', i.e., all nominal Euprymna species, the modified ventral pedicels of Boletzkyola gen. nov. display a modification (thick horn-like instead of papilla-like) and, more importantly, its hectocotylus distal part suckers are carried by regular pedicels (i.e., not columnar). The affinity with Rondeletiola, fostered by the presence of similar visceral light organs, is just apparent. In fact, those organs are quite different from each other (see Remarks in the description of Group C hectocotylus). Furthermore, the copulatory apparatus and the bursa copulatrix of this genus differ completely from those of Rondeletiola.

\section{Remarks}

The hectocotylus of Boletzkyola gen. nov. is the least modified among Sepiolinae, hence may be primitive. In addition, the morphology of its visceral light organ may reflect incomplete development of the two-kidney-shaped arrangement that is typical of the subfamily. Both traits, as well as the small body size of Boletzkyola knudseni gen. et comb. nov. - seemingly the smallest among Sepiolinae: males mature at $8.5 \mathrm{~mm}$ mantle length - suggests that the evolution of this species might have been fostered by heterochronic development.

Eumandya gen. nov.

urn:1sid:zoobank.org:act:6FB7B832-3CFA-4914-842A-A526390BFCFD

Fig. 9 (the generic name used in the caption is the former one)

\section{Type species}

Euprymna pardalota Reid, 2011, here designated.

\section{Diagnosis}

Sepiolinae with fins rounded; their length about half mantle length. Arm suckers in two longitudinal rows. Tentacle club suckers in 6 to 14 longitudinal rows. Mantle-head occipital band broad, extending over the ocular globes. A pair of kidney-shaped photophores on ventral surface of ink-sac. Gladius absent. Ventral mantle margin faintly sinuate or with slightly deep funnel indentation. Hectocotylus (male left arm I) bipartite: proximal part, occupying $2 / 3$ to $1 / 2$ of arm, with regular suckers, except for pedicel of $3^{\text {rd }}$ sucker in ventral row lengthened, papilla-like (may bear vestigial sucker at its tip); distalmost part, occupying 
$1 / 3$ to $1 / 2$ of arm distally, with lengthened columnar sucker pedicels, closely packed longitudinally bearing reduced suckers and not connected with each other by any web. Female bursa copulatrix pouch-like.

\section{Included species}

Euprymna pardalota (Reid, 2011) gen. et comb. nov., E. parva (Sasaki, 1914) gen. et comb. nov. and E. phenax (Voss, 1962) gen. et com. nov.

\section{Etymology}

This genus is named in honour of Amanda Reid (Australian Museum Research Institute, Sydney) for her outstanding contribution in the field of cephalopod taxonomy, including Sepiolinae. The generic name is derived by the combination of Mandy, the diminutive name by which she is known to her friends and colleagues, and the prefix Eu- in order to keep the assonance with the sister genus Euprymna. Gender feminine.

\section{Discussion of affinities}

The members of Eumandya gen. nov., namely parva, pardalota and phenax, were formerly assigned to Euprymna because of the palisaded distalmost part of the hectocotylus, which, despite minor differences, is a unique feature of the clade (Eumandya gen. nov., Euprymna). In addition to the readily evident difference in number of longitudinal sucker rows on arms, i.e., biseriate arrangement in Eumandya gen. nov. vs tetraseriate arrangement in Euprymna, minor differences include the lack of well-developed fleshy caps on the columnar suckers and the lack of lengthwise connections between the ventral columnar pedicels in the former genus. An additional sign of possible hectocotylian primordiality in Eumandya gen. nov. is the presence of one-single-modified-stalk in the copulatory apparatus; in most Euprymna s.s. species it is composed of two or three papillae.

\section{Remarks}

Eumandya pardalota gen. et comb. nov. and E. parva gen. et comb. nov. are deemed sister species (Reid, pers. com.; Sanchez et al. 2019). The latter authors rightly removed parva from Sepiola, as previously understood, based on both morphological features and genetic analyses (Sanchez et al. 2019). Their decision is congruous with both the absence of modified dorsal sucker pedicels in the formation of the copulatory apparatus of the hectocotylus and the presence of palisaded suckers in its distalmost part, which characters do not pertain to Sepiola. The distribution of the members of Eumandya gen. nov. is limited to the eastern Indian-western Pacific Oceans.

\section{Euprymna Steenstrup, 1887}

Fig. 7

Euprymna Steenstrup, 1887a: 43.

\section{Type species}

Inioteuthis morsei Verrill, 1881, by subsequent designation.

\section{Diagnosis}

Sepiolinae with fins rounded; their length about half mantle length. Arm suckers in 4, exceptionally 8 longitudinal rows. Tentacle club with numerous minute suckers in a few tens of longitudinal rows. Mantle-head occipital band broad, extending over the ocular globes. A pair of kidney-shaped photophores on ventral surface of ink-sac. Gladius absent. Ventral mantle margin slightly sinuate, without any deep funnel indentation. Hectocotylus (male left arm I) thicker than right arm I, bipartite: proximal part, 
occupying $1 / 5$ to $1 / 2$ of arm, with regular suckers, except for 1-3 modified pedicels (may bear vestigial suckers), lengthened papilla-like, in $3^{\text {rd }}$ to $5^{\text {th }}$ position of ventral sucker row; distalmost part, occupying $1 / 2$ to $4 / 5$ of arm distally, with lengthened columnar sucker pedicels, closely packed to form longitudinal palisades, bearing at tip embedded suckers that are partially covered by fleshy caps, number of palisades proximally equal to that of regular sucker rows but reduced toward arm extremity. Female bursa copulatrix pouch-like.

\section{Included species}

Euprymna morsei (Verrill, 1881), E. albatrossae, Voss, 1962, E. berryi Sasaki, 1929, E. brenneri Sanchez et al., 2019, E. hoylei Adam, 1986, E. hyllebergi, Nateewathana, 1997, E. megaspadicea Kubodera \& Okutani, 2002, E. penares (Gray, 1849), E. scolopes Berry, 1913, E. stenodactyla (Grant, 1833) and E. tasmanica (Pfeffer, 1884).

\section{Remarks}

Some nominal tetraseriate sucker species are deemed unresolved (cf. Norman \& Lu 1997). The biseriate sucker arm E. parva, E. pardalota and E. phenax, were removed from this genus to be placed into Eumandya gen. nov. (see above). The species in Euprymna are distributed in tropical and temperate waters of the Indo-West Pacific region (Norman \& Lu 1997; Nateewathana 1997; Kubodera \& Okutani 2002; Reid 2011).

Inioteuthis Verrill, 1881

Fig. 12

Inioteuthis Verrill, 1881: 417.

\section{Type species}

Inioteuthis japonica Verrill, 1881, by subsequent designation.

\section{Diagnosis}

Sepiolinae with fins rounded; their length about half mantle length. Suckers biseriate on all arms. Tentacle club suckers in 8 to 10 longitudinal rows. Mantle-head occipital band narrow (not reaching over the ocular globes). Visceral photophores absent. Gladius absent. Ventral mantle margin slightly sinuate, without any deep funnel indentation. Hectocotylus (male left arm I) tripartite: basal part with three suckers, two ventral and one dorsal; copulatory apparatus broadly enlarged, ear-shaped, involving about six dorsal and seven ventral modified sucker pedicels; dorsal pedicels (may bear vestigial suckers) lengthened, rolled ventrally, joined by a broad web proximally crossing the arm oral face to reach ventral formation of three horn-like pedicels, connected with each other by narrow web, so that a webbed structure delimits meso-proximally a hollow; proximal horn-like pedicels of ventral row followed distally by a void hence by about four deeply modified pedicels combined into a trough-like formation; distal part with several enlarged suckers in ventral row, first one very large, laying on trough-like structure of copulatory apparatus. Female bursa copulatrix pouch-like.

\section{Included species}

Inioteuthis japonica Verrill, 1881 and I. maculosa Goodrich, 1896.

\section{Remarks}

An Indo-Pacific genus that presently includes two species (see above). A third species usually listed in this genus, namely Inioteuthis capensis Voss, 1962, in fact does not belong to it (Young \& Vecchione 
2004), since according to its original description I. capensis bears a roundish light organ embedded in the ink sac, a trait that does not pertain to Inioteuthis. Hence, capensis is excluded from this genus and placed in Rondeletiola (see below).

Lusepiola gen. nov.

urn:1sid:zoobank.org:act:1520B148-44E4-4B35-9BA1-8F7C91086E18

Figs $8 \mathrm{~A}, 13$ (the generic name used in the captions is the former one)

\section{Type species}

Sepiola birostrata Sasaki, 1918, here designated.

\section{Diagnosis}

Sepiolinae with fins rounded with large anterior lobe, which may reach the anterior mantle margin; their length about $1 / 2$ to $2 / 3$ mantle length. Suckers biseriate on all arms. Tentacle club suckers in 4 to 8 longitudinal rows. Mantle-head occipital band narrow (not reaching over the ocular globes). A pair of kidney-shaped photophores on ventral surface of ink sac. Gladius absent. Ventral mantle margin slightly sinuate, without any deep funnel indentation. Hectocotylus (male left arm I) tripartite: basal part with four regular suckers in two rows; copulatory apparatus with modified sucker-less pedicels: two ventral pedicels horn-like, aligned, directed distally and slightly laterally, and two dorsal pedicels flattened, fused with each other and directed ventrally, adhering to the oral arm surface and to the base of both ventral horns to form a concave pad; distal part with sucker pedicels of both rows leaf-like, lengthened, widened, triangular- or squarish-shaped, flattened promixo-distally, their bases inserted transversally on arm oral surface, except for distalmost suckers with regular short pedicels; in several preserved specimens distal part rotated towards right dorsal arm. Female bursa copulatrix pouch-like.

\section{Included species}

Lusepiola birostrata (Sasaki, 1918) gen. et comb. nov. and L. trirostrata (Voss, 1962) gen. et comb. nov.

\section{Etymology}

This genus is dedicated to Chung Cheng Lu (Museum of Victoria, Melbourne, Australia and National Chung Hsing University, Taichung, Taiwan), in recognition of his enormous contribution to teuthology, including Sepiolinae systematics; its name derives from the combination of Lu's family name with Sepiola, a closely related genus. Gender feminine.

\section{Discussion of affinities}

Lusepiola gen. nov., Euprymna, Eumandya gen. nov. and Boletzkyola gen. nov. all possess a closed bursa copularix, a clear indication of their affinity. However, Lusepiola gen. nov. differs from the other three genera because the formation of its hectocotylus copulatory apparatus involves modified sucker pedicels from both the ventral and dorsal rows. It differs from Sepiola s.s., from which its species were removed, primarily because of the different type of bursa copulatrix; moreover, the basal part of its hectocotylus bears four suckers (two complete rows) instead of three. The peculiarly modified pedicels in the distal part of the hectocotylus separates Lusepiola gen. nov. from all other sepioline genera.

\section{Remarks}

The species in this genus, namely L. birostrata gen. et comb. nov. and L. trirostrata gen. et comb. nov., are distributed in the western Pacific from the Okhotsk Sea to Singapore (Reid \& Jereb 2005; Okutani 2015). 
Rondeletiola Naef, 1921

Figs 16-17

Rondeletiola Naef, 1921: 536.

\section{Type species}

Sepietta minor Naef, 1912, by monotypy.

\section{Diagnosis}

Sepiolinae with fins bluntly angled laterally; their length about half mantle length. Suckers biseriate on all arms. Tentacle club suckers in 16 longitudinal rows. Mantle-head occipital band narrow (not reaching over the ocular globes). Ventral mantle margin slightly sinuate, without any deep funnel indentation. Gladius absent. Unpaired visceral photophore on ventral surface of ink sac, slightly oval, clearly derived from paired light organs joined in sagittal plane. Hectocotylus (male left arm I) tripartite: basal part with three suckers, two ventral and one dorsal; copulatory apparatus with transverse formation of two ventral and two dorsal modified suckerless pedicels all four of them fused at their bases, ventral-most strongly developed hook-like, others hardly developed, dorsal pedicels forming most part of transverse crest; distal part lacking first two ventral suckers, some proximal suckers enlarged in both rows. Female bursa copulatrix roughly ear-shaped, devoid of cover.

\section{Included species}

Rondeletiola minor (Naef, 1912) and R. capensis (Voss, 1962).

\section{Remarks}

This genus is widely distributed from the NE Atlantic and Mediterranean, throughout the E Atlantic, to the South African part of the Indian Ocean. It is characterized among the sepiolines of this area by its unique visceral light organ, that differs from that of Boletzkyola gen. nov. (compare with the description of the latter genus). Rondeletiola is sister genus to Sepietta (Bello 1998). The species Inioteuthis capensis is re-assigned to Rondeletiola fide Vecchione \& Young (2004) and Reid (pers. com.).

Sepietta Naef, 1912

Fig. 18

Sepietta Naef, 1912: 248.

Type species

Sepiola oweniana d'Orbigny in Férussac \& d'Orbigny, 1841, by monotypy.

\section{Diagnosis}

Sepiolinae with fins rounded or bluntly angled laterally; their length about half mantle length. Suckers biseriate on all arms. Tentacle club suckers in 12 or more longitudinal rows. Mantle-head occipital band narrow (not reaching over the ocular globes). Ventral mantle margin slightly sinuate, without any deep funnel indentation. Gladius present, reduced. Visceral photophores absent. Hectocotylus (male left arm I) tripartite: basal part with three or four suckers, two ventral and one or two dorsal; copulatory apparatus with transverse formation of two ventral and two dorsal modified suckerless pedicels of various degrees of development, all four of them fused at their bases, ventral-most one longest and hook-shaped; distal part with some proximal suckers of dorsal row enlarged, wide space between the two sucker rows (Naef 1923). Female bursa copulatrix roughly ear-shaped, devoid of cover. 


\section{Included species}

Sepietta oweniana (d'Orbigny in Férussac \& d'Orbigny, 1841), S. neglecta Naef, 1916 and S. obscura Naef, 1916.

\section{Remarks}

This is a well-established genus distributed in the NE Atlantic Ocean and the Mediterranean. Its most evident character is the lack of any visceral light organ, which is a derived condition, i.e., light organs secondarily lost. Sepietta oweniana and S. neglecta are sister species (Bello 2019a) and are distinguished from S. obscura, in addition to hectocotylian characters, by their fin shape (that is bluntlyangled in the former ones and rounded in the latter), as well as by the number of longitudinal sucker rows on tentacle clubs (fewer in the latter) and the occurrence of only three suckers in the basal part of the S. obscura hectocotylus. Sepietta obscura, contrary to the other two species, dwells in shallow depths and has a narrower distribution, in the Atlantic Lusitanian waters and the Mediterranean Sea (Bello 2019a).

\section{Dichotomous identification key to the genera of Sepiolinae}

In the following key, characters valid for both sexes were used whenever possible (Atl. = Atlantic; Med. $=$ Mediterranean).

1. Four or more longitudinal rows of suckers on regular arms

Euprymna Steenstrup, 1887 (Indo-Pacific)

- Two longitudinal rows of suckers on regular arms (in a few species the ventral arm tips may bear more than two rows)

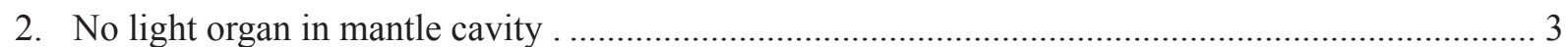

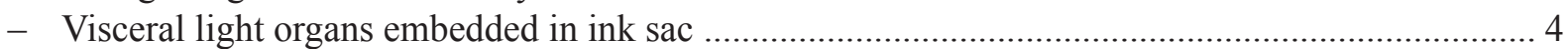

3. Twelve or more longitudinal rows of suckers on tentacle clubs. Copulatory apparatus of hectocotylus a transverse crest formed by four modified sucker pedicels, with ventral hook. Female bursa copulatrix ear-like (open type) ........................................... Sepietta Naef, 1912 (NE Atl. to Med.)

- Eight to ten longitudinal rows of suckers on tentacle clubs. Copulatory apparatus of hectocotylus wide, ear-shaped, formed by many more than four modified sucker pedicels, dorsal and three proximo-ventral ones joined by web. Female bursa copulatrix pouch-like (closed type)

Inioteuthis Verrill, 1818 (Indo-Pacific)

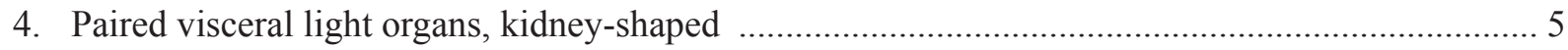

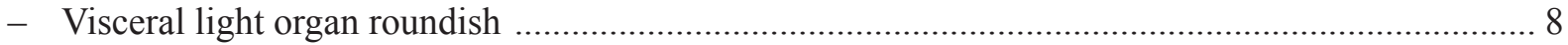

5. Fins much longer than 50\% mantle length, anteriorly almost reaching mantle margin. Distal part of hectocotylus with sucker pedicels leaf-like, latero-laterally wide

Lusepiola gen. nov. (Indo-Pacific)

- Fins about 50\% mantle length. Sucker pedicels in distal part of hectocotylus different from above, either regular or columnar

6. Hectocotylus with only one modified ventral sucker pedicel, papilla-like, in copulatory apparatus, distalmost part palisaded; female bursa copulatrix pouch-like (closed type)

Eumandya gen. nov. (Indo-Pacific)

- Hectocotylus with four or more modified sucker pedicels, both dorsal and ventral, in copulatory apparatus and distal part with regular pedicels, a few suckers may be enlarged; female bursa copulatrix ear-like (open type) 
7. Ventral mantle margin slightly sinuate; copulatory apparatus of the hectocotylus a high transverse crest formed by two dorsal and two modified sucker pedicels, elongated to about the same length and fused with each other throughout their length (additional poorly developed mesial pedicels may occur in a few species)

Sepiola Leach, 1817 (NE Atl. to Med.)

- Ventral mantle margin markedly sinuate with deep funnel indentation, protruding anteriorly on each side of funnel; copulatory apparatus of the hectocotylus with two modified ventral pedicels separate from dorsal ones, the dorsal-most ones mesially protruding towards the right arm I

Adinaefiola gen. nov. (NE Atl. to Med.)

8. Visceral light organ shape approximatively round; 16 longitudinal rows of suckers on tentacle clubs; copulatory apparatus of the hectocotylus formed by two dorsal and two ventral modified sucker pedicels fused into transverse low crest, ventral-most pedicel a strong hook ................................................. Rondeletiola Naef, 1921 (Med., NE Atl. to SW Indian Ocean)

- Visceral light organ cordiform with two anterior lobes; 8 longitudinal rows of suckers on tentacle clubs; copulatory apparatus of the hectocotylus formed by three ventral modified sucker pedicels, horn-like: Boletzkyola gen. nov. (West Africa)

\section{Tables of diagnostic features to the genera of Sepiolinae}

Tables 1 and 2 may be used as diagnostic tables to the genera of Sepiolinae considering the following correspondences: Group A / 2-Euprymna = Eumandya gen. nov.; Group B / 4-Euprymna = Euprymna; Group C / S. knudseni = Boletzkyola gen. nov.; Group D / Inioteuthis = Inioteuthis; Group E / S. birostratagroup = Lusepiola gen. nov.; Group F / S. ligulata $=$ Adinaefiola gen. nov.; Group G / S. aurantiacagroup = Adinaefiola gen. nov.; Group H / Rondeletiola $=$ Rondeletiola $;$ Group I / Sepietta $=$ Sepietta; Group J / S. atlantica-group = Sepiola .

\section{Discussion}

The results show that polyphyly among Sepiola is more extensive than previously supposed (Bello, 2005), since, in addition to the Indo-Pacific species of 'Sepiola', some Atlantic-Mediterranean species (aurantiaca, knudseni, ligulata and pfefferi) were found to be inappropriately placed in their nominal genus clade. The former genus Euprymna was also shown to encompass two different clades, one including the species with tetraseriate arm suckers and the other those biseriate. Hence the need to erect four new genera in order to adhere to the present cladogram of Sepiolinae to better reflect the supposed monophyletic groups. In summary, this subfamily, now containing nine genera, four of which new (Adinaefiola, Boletzkyola, Eumandya and Lusepiola genera nova), is much more diverse than previously assumed.

Incidentally, it is noteworthy that both nominal genera Sepiola and Euprymna have been used for more than a century to the present as omnibus or catch-all genera, into which to constrain newly discovered sepioline species. The most perplexing cases were the assignment of knudseni, despite its sagittal patently cordiform visceral light organ, to Sepiola, a genus characterized by paired kidney-shaped light organs, and the assignment of capensis, in spite of its evident roundish visceral light organ and comparatively inconspicuous copulatory apparatus, to Inioteuthis, a genus devoid of light organs and with a most conspicuous hectocotylian copulatory apparatus. Accordingly, the latter species had been already removed from Inioteuthis and re-assigned to Rondeletiola (Young \& Vecchione 2004), although several authors have maintained it in its original genus.

The results show that each sepioline genus, including the new ones, displays a unique genus-specific hectocotylus; however, generic differences are also corroborated by non-hectocotylian diagnostic characters (see below). In this respect, Steenstrup (1857) was perfectly right in stating that the 
hectocotylus bears its peculiar characters in each natural genus. The hectocotylian diversity can be also recognized at the species level in some genera, e.g., Adinaefiola gen. nov. (cf. Naef 1923; Goud \& de Heij 2012, about aurantiaca/pfefferi), Sepietta (cf. Naef 1923; Bello 1995) and Sepiola (cf. Bello 2013, where the $S$. atlantica-group corresponds to the present Sepiola s.s.).

The here proposed infra-subfamilial hectocotylus-based systematics of Sepiolinae is soundly backed by additional morphological characters, primarily: the shape of female bursa copulatrix, presence/absence and shape of visceral light organs and presence/absence of a gladius, all traits that proved essential in recognising different clades and tracking phylogenetic groups. Incidentally, the incomplete or suspended development of visceral light organs in Boletzkyola knudseni gen. et comb. nov. and Rondeletiola minor, which are the smallest among the Atlantic-Mediterranean Sepiolinae, might be related to a heterochrony in body development.

Moreover, the present morphology-based systematics is in good agreement with genetic studies from the last decade (Groenenberg et al. 2009; Lindgren et al. 2012; Sanchez et al. 2019). In particular, Groenenberg et al. (2009) and Sanchez et al. (2019) produced localized but accurate cladograms, based on their own molecular and morphological examinations. The former examined several AtlanticMediterranean species, highlighting a clear-cut dichotomy between the Sepiola spp. clade and the clade including Sepietta spp. + A. ligulata gen. et comb. nov. + A. pfefferi gen. et comb. nov., that is (Sepiola (A. ligulata, A. pfefferi, Sepietta)) (Groenenberg et al. 2009: fig. 5) (generic names updated to present results). The exclusion of both Adinaefiola gen. nov. species from Sepiola agrees well with the present results; however, those two species were not placed together in one clade as in the present paper. As for the Indo-Pacific Sepiolinae, Sanchez et al. (2019) examined specimens of Lusepiola birostrata gen. et comb. nov., five Euprymna species, Eumandya parva gen. et comb. nov. and another, unidentified, biseriate sucker species. Their cladogram, that is (Lusepiola (Euprymna, Eumandya gen. nov.)) (Sanchez et al. 2019: fig. 3), is in perfect agreement with the present results.

It must be emphasized that the overall molecular-based research on Sepiolinae has been hindered by two drawbacks. First, no study has yet included any data for Inioteuthis or Boletzkyola gen. nov.; a problem which may be solved in the near future. Second, and more importantly, numerous specimens used in genetic research were misidentified (cf. Groenenberg et al. 2009; Lindgren et al. 2012; Allcock et al. 2014; Sanchez et al. 2019); unfortunately, because in many cases voucher specimens used for molecular studies have not been retained in accessible repositories, some of these misidentifications can never be checked and corrected.

Bello (2019a) pointed out how the speciation, hence the generic and specific diversification within Sepiolinae, was most probably caused by the genus- and species-specific lock-and-key copulatory organs (i.e., the male hectocotylus and the female bursa copulatrix) as a means of preventing hybridization among allied sympatric species, and thus reinforcing reproductive isolation (Hutchinson 1959). (Incidentally, genetic-based hectocotylian anomalies, which may be less rare than generally believed, may well be a main source for speciation in Sepiolinae; Bello 2019b.) In this respect, a clear-cut phylogenetic dichotomy exists between the groups of genera displaying either the closed or open types of bursa copulatrix, which represent the plesiomorphic and apomorphic character states, respectively. A parallel dichotomy also affects the male counterpart, the hectocotylus. In some genera with a closed bursa copulatrix, namely Eumandya gen. nov., Euprymna and Lusepiola gen. nov., the distal part of the hectocotylus is characterized by very enlarged sucker pedicels, a feature possibly necessary to keep the bursa copulatrix entrance open while the spermatophores, carried by the copulatory apparatus, are deposited there. In the other closed-bursa copulatrix genera, namely Boletzkyola gen. nov. and Inioteuthis, the distal part of the hectocotylus is not conspicuously enlarged, possibly because their bursae copulatrices are smaller than in the above-mentioned genera (author's pers. obs.). In contrast, 
members of the open bursa copulatrix group (Adinaefiola gen. nov., Rondeletiola, Sepietta and Sepiola) have the sucker pedicels in the hectocotylus distal part not or only moderately lengthened. Hence, the evolution of both the bursa copulatrix and the hectocotylus are coupled, at least in these characters. A further fine example of coevolutionary correspondence between these sex-specific organs occurs in Adinaefiola ligulata gen. et comb. nov., where the bursa copulatrix, in the left mantle cavity, protrudes into the right cavity with a large caecum, which during the ventral mating - that is male back underneath female venter, with hectocotylus (on the left side) retroflected and inserted into the bursa copulatrix (on the left side too) - corresponds to and most probably enfolds the ligula of the hectocotylian copulatory apparatus. Incidentally, the bursa copulatrix morphology is fairly well known in most NE AtlanticMediterranean sepioline species (e.g., Naef 1923; Bello 2013) whereas it is virtually unknown in the Indo-Pacific ones, apart from the concise observations in the present paper.

In recent times, lock-and-key mating mechanisms have been subjected to criticism and are no longer believed to depend on natural selection exclusively but rather on a combination of natural and sexual selection (Masly 2012; Brennan \& Prum 2015). Nevertheless, whatever the evolutionary driving forces behind this selection, in the case of Sepiolinae one can safely state that the genus- and/or species-specific hectocotylus-bursa copulatrix pairs are the result of coevolutionary processes at least regarding the dichotomy between the Indo-Pacific and NE Atlantic-Mediterranean generic macrogroups and few other specific cases. Indeed, looking more closely at the bursa copulatrix-hectocotylus coevolution at the species level in the NE Atlantic-Mediterranean generic macro-group, one may realize that - apart from the specific case of A. ligulata gen. et comb. nov - the bursa copulatrix does not strictly parallel the high diversification of the hectocotylus. There is just a general trend in size, such that species with a larger hectocotylus have a larger bursa copulatrix (such as in the pairs $S$. owenianaobscura and A. ligulata-aurantiaca, where the first species of each pair has larger organs) but this trend is quite feeble. This observation supports the assumption that, in the NE Atlantic-Mediterranean group of genera, the male hectocotyli evolved faster than female bursae copulatrices and the latter lagged somewhat behind. In a case study of Gnaphosidae (Araneae), animals that display genital complexity more advanced in males than in females similar to that seen in Atlantic-Mediterranean Sepiolinae, Azevedo et al. (2018) showed that the evolution of copulatory organs is mainly based on cryptic female choice mechanisms. Thus, females cryptically chose males based mainly on stimuli that male genitalia produce regardless of female genital shape (Eberhard 2015). In summary, in Sepiolinae it appears that a fairly strict genital coevolution may have occurred at the macroevolutionary level (i.e., closed bursa copulatrix/distally enlarged hectocotylus, the plesiomorphic state, evolved to open bursa copulatrix/loss of enlarged stalks in the distal hectocotylus, the apomorphic state) followed mainly by female cryptic choice mechanisms at the generic and specific levels. In this regard, it must be pointed out that the lock-and-key natural selection mechanism and the female cryptic choice mechanisms are not mutually exclusive since different processes may together affect the evolution of genital complexity (Simmons 2014). Lastly, Ah-King et al. (2014) stressed how the bias towards the study of male genitalia might hinder the understanding of female genital evolution, which is partly the case for Sepiolinae.

Furthermore, male evolution followed two separate evolutive pathways in the NE Atlantic-Mediterranean sepioline genera, where the hectocotylus and its copulatory apparatus evolution largely contributed to their diversification, and in Euprymna s.s. (apart from E. megaspadicea) where differences rather concerned the distribution of enlarged suckers in regular arms (Norman \& Lu 1997; Sanchez et al. 2019). Incidentally, Sanchez et al. (2019), who by means of genetic analyses showed some degree of separation between 'Euprymna' tetra- and biseriate sucker species, also hypothesized, based on a phylogenetic analysis of molecular characters, that the former derived from the latter. 
As shown in the Results, the diversification in Sepiolinae was largely accompanied by that of the hectocotylus, whose complexity is mainly due to the wide array of modifications of the sucker pedicels. Some Rossiinae and Heteroteuthinae as well as Sepiadariidae Fischer, 1882 (sister family of Sepiolidae; Strugnell et al. 2017), also display hectocotylian pedicel modifications, but they are by far less extensive than in Sepiolinae. The examination of hectocotylus ontogenetic development, especially that of the copulatory apparatus, provides evidence that its 'building blocks', i.e., the suckerless pedicels, are plastic to a huge extent, being capable of lengthening, widening, thickening, thinning, curving, becoming pointed or blunt, wrinkling, flattening to lamina, or fusing with each other. Such a concurrent diversity of pedicel modifications is unparalleled in any other coleoid family. Parenthetically, the complex of hectocotylian modifications is to be considered an exaptation, the adaptation of a pre-existing organ to a different function (Gould \& Vrba 1982): in Sepiolinae as well as in many other coleoid taxa, the prehensile arm became a copulatory tool (Bello 2012).

As for the phylogenetic relationships among Sepiolinae, according to Naef (1923) (Fig. 5) this taxon derived from a hypothetical Protosepiolina, sister genus to Semirossia, a member of the Rossiinae. Were this supposition true, the Rossiinae would be paraphyletic, contrary to the current views that deem it a sister clade to all the other sepiolid taxa (Young 2007). Indeed, a few sepioline plesiomorphic features are found in some rossiine genera: the character state 'tetraseriate sucker arms' of Euprymna occurs in Rossia Owen, 1835, moreover in both genera the marginal rows bear suckers slightly larger than the inner rows; both the hectocotylization of left arm I and the visceral paired light organs occur in Semirossia (although these similarities may simply be the result of convergence). Most importantly, the hectocotylian morphology of the latter genus appears much closer to Sepiolinae than to the other rossiine genera, namely Rossia, Neorossia Boletzky, 1971 and Austrorossia Berry, 1918. This detail was already pointed out by Steenstrup (1887b), who erected the genus Semirossia just because its hectocotylus was different from that of Rossia. In the former genus "the left dorsal arm becomes thickened and larger from front to back, and usually is curled backward; its suckers become smaller and much more numerous than on the right arm, being arranged in four crowded rows, except near the base, where there are but two; the sucker-stalks also become stout and cylindrical or tapered, their diameter equaling that of the suckers" (Verrill 1880: 361). These pedicels are somewhat close to the Euprymna columnar suckers. In contrast to the above described hectocotylus of Semirossia tenera, the hectocotylization in Rossia, Neorossia and Austrorossia involves both dorsal arms and consists of a glandular crest running along the ventrolateral border of those arms, without any pronounced modification of the arm sucker pedicels (Reid \& Jereb 2005). The main reason why Semirossia is placed in Rossiinae is that its dorsal mantle margin is not fused to the head. The relationships between Sepiolinae and Heteroteuthinae, its sister clade (when we disregard some incertae sedis taxa; cf. Young 2007), are fairly unclear mainly because of the poorly understood systematic situation of the latter subfamily (Allcock et al. 2014). Anyway, the heteroteuthine hectocotyli (cf. Reid \& Jereb 2005) are very different from, and by far simpler, than the sepioline ones. Additional work is necessary to aptly understand the phylogenetic relationships between Sepiolinae and the other sepiolid taxa; even more, to understand the overall systematics of Sepiolidae, including the genus Chonoteuthis Lu \& Boucher-Rodoni, 2006 and an undescribed subfamily (Young 2007), and its relationship to the sister taxon Sepiadariidae.

Moreover, knowledge of Sepiolinae itself, a most fascinating taxon, needs increased research focus. First, it is important to review the genera Eumandya gen. nov., Euprymna and Inioteuthis (much work is presently underway), in order to describe additional characters and define the species to include in them. In this respect, the status of several nomina nuda and incertae sedis species may be resolved.

A thorough examination of the closed type of bursa copulatrix is essential to establish its diversity and its role in evolution, as well as to understand its function during copulation (cf. Akalin \& Salman 2018, regarding several Mediterranean species of Sepiolinae). 
Lastly, the phylogenetic relationships within Sepiolinae should be studied in order to track the connections among its genera. In this respect, research based on genetic analyses based on reliable taxon identifications coupled with morphological investigations will prove to be of paramount importance.

\section{Acknowledgements}

Preliminary results of this paper were presented in the "Sasaki Collections" Mini-Workshop (CIAC Meeting, Hakodate, November 2015), organized by Ian Gleadall (Ai Ceph LLC and Tohoku University, Sendai, Japan); he made many specimens of Japanese sepioline species available, which were fundamental for my work, hence I am deeply grateful to him for his precious help. I thank also the colleagues participating in the workshop for the fruitful exchange of ideas, in particular Louise Allcock (Ryan Institute, National University of Ireland Galway, Galway), Mandy Reid (Malacology, Australian Museum Research Institute, Sydney) and C.C. Lu (National Chung Hsing University, Taiwan and Museum of Victoria, Australia). To these, I must add Sigurd Boletzky for the long-standing dialogue on Sepiolidae since the start of my interest in this taxon; I thank him for his continuous support.

The following collection curators, researchers and institutions are acknowledged for the loan of precious material: José Templado, Oscar Soriano and Rafael Araujo (Museo Nacional de Ciencias Naturales, Madrid, Spain); Charatsee Aungtonya (Reference Collection of the Phuket Marine Biology Center, Thailand); Kathe Jensen and Tom Schiøtte (Zoological Museum of the University of Copenhagen, Denmark); University Museum of the University of Tokyo; Yale Peabody Museum of Natural History. I warmly thank Aldo Corriero and Rosa Zupa (Department of Emergency and Organ Transplant, University of Bari, Italy) for their hospitality and assistance with taking photographs. As for photographs, I also thank Ian Gleadall for providing contacts with Mamoru Yabe (Faculty of Fisheries Sciences, Hokkaido University, Hakodate, Japan), whom I warmly thank for allowing the use of the laboratory facilities where Hidenori Shimada (same institution) helped in taking photographs of the Inioteuthis japonica types.

I am greatly indebted to Louise Allcock and Amanda Reid for critically reading and revising a first and second draft of this paper, respectively; their substantial advice significantly improved it. Moreover, Amanda Reid generously provided important unpublished observations. I am also most grateful to the anonymous reviewers for their nice words and valuable suggestions. Lastly, I thank Anthony Green (University of Bari) for kindly reviewing the English of revised parts in the manuscript.

\section{References}

Adam W. 1984. Cephalopoda from West and South Africa. Atlantide Report 13: 151-180.

Ah-King M., Barron A.B. \& Herberstein M.E. 2014. Genital evolution: why are females still understudied? PLOS Biology 12 (5): e1001851. https://doi.org/10.1371/journal.pbio.1001851

Akalin M. \& Salman A. 2018. Spermatangia implantation in the subfamily Sepiolinae (Cephalopoda: Sepiolidae). Vie et Milieu 68: 119-125.

Allcock A.L., Lindgren A. \& Strugnell J.M. 2014. The contribution of molecular data to our understanding of cephalopod evolution and systematics: a review. Journal of Natural History 49: 13731421. https://doi.org/10.1080/00222933.2013.825342

Azevedo G.H.F., Griswold C.E. \& Santos A.J. 2018. To complicate or to simplify? Phylogenetic tests of complexity trends and genital evolution in ground spiders (Araneae: Dionycha: Gnaphosidae). Zoological Journal of the Linnean Society 184: 673-694. https://doi.org/10.1093/zoolinnean/zly016

Bello G. 1995. A key for the identification of the Mediterranean sepiolids. Bulletin de l'Institut océanographique, Monaco ${ }^{\circ}$ spéc. 16: 41-55. 
Bello G. 1998. Cladistic analysis of the Atlanto-Mediterranean sepiolines (Cephalopoda: Sepiolidae) based on morphological characters. Memorie del Museo Civico di Storia Naturale di Verona (2 ${ }^{\text {nd }}$ series), Sezione Scienze della Vita 13: 81-85.

Bello G. 2005. Cladistic analysis of the Sepiolinae (Cephalopoda: Sepiolidae) based on the hectocotylus. In: Košt'ák M. \& Marek J. (eds) $2^{\text {nd }}$ International Symposium "Coleoid Cephalopods Through Time": 24-25. Charles University, Faculty of Science, Praha.

Bello G. 2011. Invalidity of the nominal species Sepietta petersii (Steenstrup 1887) and nomenclatural revision of the genus Sepietta Naef 1912 (Cephalopoda: Sepiolidae). Journal of Conchology 40: 549558.

Bello G. 2012. Exaptations in Argonautoidea (Cephalopoda: Coleoidea: Octopoda). Neues Jahrbuch für Geologie und Paläontologie 266: 85-92. https://doi.org/10.1080/00222933.2013.825342

Bello G. 2013. Description of a new sepioline species, Sepiola bursadhaesa n. sp. (Cephalopoda: Sepiolidae), from the Catalan Sea, with remarks and identification key for the Sepiola atlantica-group. Scientia Marina 77: 489-499. https://doi.org/10.3989/scimar.03720.31A

Bello G. 2015. The original descriptions of the Mediterranean taxa in the order Sepiolida (Mollusca: Cephalopoda) with notes on the validity of the specific name Sepiola rondeletii Leach, 1817. Bollettino Malacologico 51: 22-46.

Bello G. 2019a. The Mediterranean Sepiolidae (Mollusca: Cephalopoda) diversity. Biodiversity Journal 10: 389-404. https://doi.org/10.31396/Biodiv.Jour.2019.10.4.389.404

Bello G. 2019b. Teratological anomalies in the hectocotylus of Sepietta oweniana (Cephalopoda: Sepiolidae). Vita Malacologica 18: 72-76.

Bello G. \& Salman A. 2015. Description of a new sepioline species, Sepiola boletzkyi sp. nov. (Cephalopoda: Sepiolidae), from the Aegean Sea. European Journal of Taxonomy 144: 1-12. https://doi.org/10.5852/ejt.2015.144

Boletzky S.V. 1970. On the presence of light organs in Semirossia Steenstrup, 1887 (Mollusca: Cephalopoda). Bulletin of Marine Science 20: 374-388.

Brennan P.L.R. \& Prum R.O. 2015. Mechanisms and evidence of genital coevolution: the roles of natural selection, mate choice, and sexual conflict. Cold Spring Harbor Perspectives in Biology 7: a017749. https://doi.org/10.1101/cshperspect.a017749

Cuccu D., Mereu M., Cannas R., Sanna I., Cau A. \& Jereb P. 2009. Variability in Sepietta oweniana (Cephalopoda: Sepiolidae) hectocotyli. Italian Journal of Zoology 76: 189-193.

https://doi.org/10.1080/11250000802346241

Eberhard W.G. 2015. Cryptic female choice and other types of post-copulatory sexual selection. In: Peretti A.V. \& Aisenberg A. (eds) Cryptic female choice in arthropods: 1-26. Springer, Heidelberg. https://doi.org/10.1007/978-3-319-17894-3_1

Foster J.S., Boletzky S.v. \& McFall-Ngai M.J. 2002. A comparison of the light organ development of Sepiola robusta Naef and Euprymna scolopes Berry (Cephalopoda: Sepiolidae). Bulletin of Marine Science 70: 141-153.

Goud J. \& de Heij A. 2012. Mediterranean Sepiola aurantiaca Jatta, 1896, versus the NE Atlantic Sepiola pfefferi Grimpe, 1921 (Cephalopoda, Sepiolinae). Basteria 76: 1-11.

Gould S.J. \& Vrba E.S. 1982. Exaptation-a missing term in the science of form. Paleobiology 8: 4-15. 
Groenenberg D.S.J., Goud J., Heij A. de \& Gittenberger E. 2009. Molecular phylogeny of North Sea Sepiolinae (Cephalopoda: Sepiolidae) reveals an overlooked Sepiola species. Journal of Molluscan Studies 75: 361-369. https://doi.org/10.1093/mollus/eyp032

Heij A. de \& Goud J. 2010. Sepiola tridens spec. nov., an overlooked species (Cephalopoda: Sepiolidae) living in the North Sea and north-eastern Atlantic Ocean. Basteria 74: 51-62.

Hutchinson G.E. 1959. Homage to Santa Rosalia or Why there are so many kinds of animals? The American Naturalist 93: 145-159.

Jatta G. 1896. I Cefalopodi viventi nel Golfo di Napoli. Fauna und Flora des Golfes von Neapel 23. R. Friedländer \& Sohn, Berlin. https://doi.org/10.5962/bhl.title.51597

Kubodera T. \& Okutani T. 2002. A new species of Bobtail Squid, Euprymna megaspadicea, from Okinawa, Japan. Venus 61: 159-168.

Leach W.E. 1817. Synopsis of the Orders, Families, and Genera of the Class Cephalopoda. The Zoological Miscellany 3 (30): 137-141.

Lindgren A.R., Pankey M.S., Hochberg F.G. \& Oakley T.H. 2012. A multi-gene phylogeny of Cephalopoda supports convergent morphological evolution in association with multiple habitat shifts in the marine environment. BMC Evolutionary Biology 12: 129. http://www.biomedcentral.com/1471-2148/12/129

Lu C.C. \& Boucher-Rodoni R. 2006. A new genus and species of sepiolid squid from the waters around Tonga in the central South Pacific (Mollusca: Cephalopoda: Sepiolidae). Zootaxa 1310: 37-51. https://doi.org/10.11646/zootaxa.1310.1.2

Masly J.P. 2012. 170 years of "lock-and-key": genital morphology and reproductive isolation. International Journal of Evolutionary Biology 2012: ID 247352. https://doi.org/10.1155/2012/247352

Minelli A. 1993. Biological Systematics: the State of the Art. Chapman \& Hall, London.

MolluscaBase. 2018a. Euprymna Steenstrup, 1887. Available through World Register of Marine Species from http://www.marinespecies.org/aphia.php?p=taxdetails\&id=341426 [accessed 22 Dec. 2018].

MolluscaBase. 2018b. Inioteuthis Verrill, 1881. Available through World Register of Marine Species from http://www.marinespecies.org/aphia.php?p=taxdetails\&id=341435 [accessed 22 Dec. 2018].

MolluscaBase. 2018c. Rondeletiola Naef, 1921. Available through World Register of Marine Species from http://www.marinespecies.org/aphia.php?p=taxdetails\&id=138480 [accessed 22 Dec. 2018].

MolluscaBase. 2018d. Sepietta Naef, 1912. Available through World Register of Marine Species from http://www.marinespecies.org/aphia.php?p=taxdetails\&id=138482 [accessed 22 Dec. 2018].

MolluscaBase. 2018e. Sepiola Leach, 1817. Available through World Register of Marine Species from http://www.marinespecies.org/aphia.php?p=taxdetails\&id=138483 [accessed 22 Dec. 2018].

Naef A. 1912a. Teuthologische Notizen. 1. Die Familien der Myopsiden; 2. Die Gattungen der Sepioliden. Zoologischer Anzeicher 39: 241-248.

Naef A. 1912b. Teuthologische Notizen. 3. Die Arten der Gattungen Sepiola und Sepietta. Zoologischer Anzeiger 39: 262-271.

Naef A. 1912c. Teuthologische Notizen. 7. Zur Morphologie und Systematik der Sepiola- und SepiettaArten. Zoologischer Anzeiger 40: 78-85.

Naef A. 1916. Ueber neue Sepioliden aus dem Golf von Neapel. Pubblicazioni della Stazione Zoologica di Napoli 1: 1-10.

Naef A. 1921. Das System der dibranchiaten Cephalopoden und die mediterranen Arten derselben. Mitteilungen aus der Zoologischen Station zu Neapel 22: 527-542. 
Naef A. 1923. Die Cephalopoden. Fauna und Flora des Golfes von Neapel 35 (1): 1-863. [English translation by Mercado A. 1972; Smithsonian Institution, Washington D.C.: 1-917]

Nateewathana A. 1997. The Sepiolidae (Cephalopoda) of the Andaman Sea, Thailand, with description of Euprymna hyllebergi sp. nov. Phuket Marine Biological Center Special Publication 17: 465-481.

Nishiguchi M.K., Lopez J.E. \& Boletzky S.v. 2004. Enlightenment of old ideas from new investigations: more questions regarding the evolution of bacteriogenic light organs in squids. Evolution \& Development 6: 41-49. https://doi.org/10.1111/j.1525-142X.2004.04009.x

Norman M.D. \& Lu C.C. 1997. Redescription of the southern dumpling squid Euprymna tasmanica and a revision of the genus Euprymna (Cephalopoda: Sepiolidae). Journal of the Marine Biological Association of the United Kingdom 77: 1109-1137. https://doi.org/10.1017/S0025315400038662

Okutani T. 2015. Cuttlefishes and Squids of the World (New Edition). Tokai University Press, Tokay.

Okutani T. \& Horita E. 1987. Identity of Euprymna berryi Sasaki 1929 (Cephalopoda: Sepiolidae). Venus 46: 91-107.

Reid A. 2011. Euprymna pardalota sp. nov. (Cephalopoda: Sepiolidae), a new dumpling squid from northern Australia. The Beagle, Records of the Museums and Art Galleries of the Northern Territory 27: $135-142$.

Reid A. \& Jereb P. 2005. Family Sepiolidae. In: Jereb P. \& Roper C.F.E. (eds) Cephalopods of the world. An annotated and illustrated catalogue of species known to date. Vol. 1. FAO Species Catalogue for Fishery Purposes 4 (1): 153-203.

Reid A., Jereb P. \& Roper C.F.E. 2005. Family Sepiidae. In: Jereb P. \& Roper C.F.E. (eds) Cephalopods of the world. An annotated and illustrated catalogue of species known to date. Vol. 1. FAO Species Catalogue for Fishery Purposes 4 (1): 57-152.

Rondeletius G. 1554. Libri de Piscibus Marinis, in quibus verce Piscium effigies expressce sunt. Matthias Bonhomme, Lugduni [Lyon].

Sanchez G., Jolly J., Reid A., Sugimoto C., Azama C., Marlétaz F., Simakov O. \& Rokhsar D.S. 2019. New bobtail squid (Sepiolidae: Sepiolinae) from the Ryukyu islands revealed by molecular and morphological analysis. Communications Biology 2: 465. https://doi.org/10.1038/s42003-019-0661-6

Sasaki M. 1929. A monograph of the dibranchiate cephalopods of the Japanese and adjacent waters. Journal of the College of Agriculture, Hokkaido Imperial University 20 suppl: 1-357.

Simmons L.W. 2014. Sexual selection and genital evolution. Austral Entomology 53: 1-17. https://doi.org/10.1111/aen.12053

Steenstrup J. 1857. Hectocotylus-formation in Argonauta and Tremoctopus explained by Observations on similar Formations in the Cephalopoda in general. The Annals and Magazine of Natural History. $2^{\text {nd }}$ series 20: $81-114$.

Steenstrup J. 1887a. Notæ Teuthologicæ. 6. Species generis Sepiola Maris Mediterranei. Oversigt over det Kongelige Danske Videnskabernes Selskabs Forhandlinger 1887: 47-66.

Steenstrup J. 1887b. Notæ Teuthologicæ. 7. Sepioloidea D’Orb. 1845. Fér. D’Orb. Pl. III. f. 10-18. Oversigt over det Kongelige Danske Videnskabernes Selskabs Forhandlinger 1887: 67-126.

Steenstrup J. 1900. Heteroteuthis Gray, with remarks on the Rossia-Sepiola family in general. Kongelige Danske Videnskabernes Selskabs Skrifter 6: 283-300. [English translation in: Volsøe A., Knudsen J. \& Rees W. (eds) 1962. The Cephalopods Papers of Japetus Steenstrup: 309-325. Danish Science Press Ltd, Copenhagen.] 
Strugnell J.M., Hall N.E., Vecchione M., Fuchs D. \& Allcock A.L. 2017. Whole mitochondrial genome of the Ram's Horn Squid shines light on the phylogenetic position of the monotypic order Spirulida (Haeckel, 1896). Molecular Phylogenetic and Evolution 109: 296-301. https://doi.org/10.1016/j.ympev.2017.01.011

Sweeney M.J. 2001. Current Classification of Recent Cephalopoda. Washington DC: National Museum of Natural History. Available from www.mnh.si.edu/cephs/newclass.pdf [accessed 4 Feb. 2011].

Takayama K. \& Okutani T. 1992. Identity of Sepiola parva Sasaki, 1913 and S. birostrata Sasaki, 1918 in the Northwest Pacific (Cephalopoda: Sepiolidae). Venus 51: 503-514.

Vecchione M. \& Young R.E. 2003. Rondeletiola Naef, 1921. Ver. 30 Nov. 2003 (under construction). The Tree of Life Web Project. Available from http://tolweb.org/Rondeletiola/20040/20003.11.30 [accessed 2 Jan. 2019].

Vecchione M. \& Young R.E. 2003. Sepiola Leach, 1817. Ver. 30 Nov. 2003 (under construction). The Tree of Life Web Project. Available from http://tolweb.org/Sepiola/20038/2003.11.30 [accessed 2 Jan. 2019].

Vecchione M. \& Young R.E. 2004. Sepiolinae Appellof, 1898. Ver. 30 Aug. 2004 (under construction). The Tree of Life Web Project. Available from http://tolweb.org/Sepiolinae/20035/2004.08.30 [accessed 2 Jan. 2019].

Verrill A.E. 1880. Notice of recent additions to the marine Invertebrata of the northeastern coast of America, with descriptions of new genera and species and critical remarks on others. Part II - Mollusca, with notes on Annelida, Echinodermata, etc., collected by the United States Fish Commission. Proceedings of the United States National Museum 3: 356-409.

https://doi.org/10.5479/si.00963801.168.356

Verrill A.E. 1881. The Cephalopods of the Northeastern Coast of America. Part II. The smaller cephalopods, including the "squids" and the octopi, with other allied forms. Transactions of the Connecticut Academy of Sciences 5 (6): 259-446.

Voss G.L. 1963. Cephalopods of the Philippines Islands. Bulletin of the United States National Museum 234: 1-180.

Young R.E. (ed.) 1996-2019. [Pages for Cephalopoda]. The Tree of Life Web Project. Available from http://tolweb.org [accessed 2 Jan. 2019].

Young R.E. 2007. Sepiolidae Leach 1817. Ver. 26 Dec. 2007 (under construction). The Tree of Life Web Project. Available from http://tolweb.org/Sepiolidae/19988/2007.12.26 [accessed 2 Jan. 2019].

Young R.E. \& Vecchione M. 2004. Inioteuthis Verrill, 1881. Ver. 2 Sep. 2004 (under construction). The Tree of Life Web Project. Available from http://tolweb.org/Inioteuthis/20042/2004.09.02 [accessed 2 Jan. 2019].

Young R.E., Sanchez C. \& Allain V. 2006. New Subfamily. New Genus. Version 24 Nov. 2006 (under construction). The Tree of Life Web Project. Available from:

http://tolweb.org/New_Genus/77759/2006.11.24 [accessed 2 Jan. 2019].

Manuscript received: 28 October 2019

Manuscript accepted: 12 March 2020

Published on: 29 May 2020

Topic editor: Rudy Jocqué

Section editor: Thierry Backeljau

Desk editor: Marianne Salaün 
Printed versions of all papers are also deposited in the libraries of the institutes that are members of the EJT consortium: Muséum national d'Histoire naturelle, Paris, France; Botanic Garden Meise, Belgium; Royal Museum for Central Africa, Tervuren, Belgium; Royal Belgian Institute of Natural Sciences, Brussels, Belgium; Natural History Museum of Denmark, Copenhagen, Denmark; Naturalis Biodiversity Center, Leiden, the Netherlands; Museo Nacional de Ciencias Naturales-CSIC, Madrid, Spain; Real Jardín Botánico de Madrid CSIC, Spain; Zoological Research Museum Alexander Koenig, Bonn, Germany; National Museum, Prague, Czech Republic. 